\title{
Global Inequality in a more educated world
}

\section{Amer Ahmed ${ }^{1} \cdot$ Maurizio Bussolo $^{1} \cdot$ Marcio Cruz $^{1,2}$ - Delfin S. Go ${ }^{1}$ • Israel Osorio-Rodarte ${ }^{1}$}

Received: 2 July 2018 / Accepted: 24 March 2020 / Published online: 20 July 2020

(C) World Bank 2020

\begin{abstract}
Better-educated and younger cohorts from developing countries are entering the global labor market. This education wave is altering the skill and geographic composition of the global labor market, and impacting income distribution, at the national and global levels. This paper analyzes how this education wave reshapes global inequality over the long run using a general-equilibrium macro-micro simulation framework that covers harmonized household surveys for almost $90 \%$ of the world population. The findings suggest that global income inequality will likely decrease by 2030. The expanding supply of better educated workers from developing countries will be a key factor, especially in supporting the reduction of income disparities between countries. The education wave will also minimize, mainly for developing countries, increases of within-country inequality linked to technological progress and its widening of wage premia.
\end{abstract}

JEL Classification D31 J11 J J31 E24

Keywords Global inequality $\cdot$ Education · Demographic trends $\cdot$ Structural change

Electronic supplementary material The online version of this article (https://doi.org/10.1007/s10888-020$09440-z)$ contains supplementary material, which is available to authorized users.

Maurizio Bussolo

mbussolo@worldbank.org

Amer Ahmed

sahmed20@worldbank.org

Marcio Cruz

marciocruz@worldbank.org

Delfin S. Go

dgo@worldbank.org

Israel Osorio-Rodarte

iosoriorodarte@worldbank.org

1 World Bank Group, Washington, DC 20433, USA

2 Federal University of Paraná, Rua XV de Novembro, 1299, Curitiba 80060-000, Brazil 


\section{Introduction}

In the next two decades, younger and better-educated cohorts are projected to contribute to the expansion of the global workforce, while older, less educated ones leave. This skill-biased expansion will also be geographically biased, as it will be composed almost exclusively of workers from developing countries. This paper estimates the size of this structural shift and shows how it could reduce global inequality by a magnitude close to that observed in the last two decades or so.

Lakner and Milanovic (2016) estimate that global inequality, as measured by the Gini index, ${ }^{1}$ dropped about 2 Gini points from 72.2 in 1988 to 70.5 in 2008. Strong economic expansion of developing countries, including the sustained growth of China and India, boosted convergence of per-capita incomes at the global level. ${ }^{2}$ And this convergence drove the reduction of global inequality, even if technological change and aging contributed to increasing inequality at the national level in many countries.

Since the fall of the Berlin Wall, a crucial factor shaping global inequality has been the rapid integration of rising working-age populations in developing countries into the world economy. In the words of Freeman (2008 and 2007), a truly global labor market took shape when China, India, and the former Soviet bloc joined the global economy, increasing the size of the labor pool from 1.5 billion workers to 2.9 billion workers. This "great doubling" of global labor, as Freeman called it, came from new entrants who were low skilled and low wage. Soaring international trade (between 1990 and 2015, the share of trade in global GDP rose by about $50 \%$ ) benefited these workers. Demand for the goods they produced went up, and so did their wages. The opposite happened for lowskilled workers in high-income countries. ${ }^{3}$

In the next two decades and for some time after that, the evolution of the global workforce will be quite different. Rather than a large entry of unskilled and low wage workers, the global labor force will register an influx of skilled workers. However, similarly to the earlier period, this influx will originate from developing countries. While in 2012, each skilled worker in high-income countries was sharing the global market with two skilled workers in developing countries; by 2030, this ratio will be one to three. ${ }^{4}$ Although this projected transformation is not another great doubling, it is still a dramatic change. The increase in the supply of skilled workers will likely drive down the education premia these workers enjoy (other things being equal), and unlike the first wave, it may affect inequality within countries in a beneficial way. This kind of result has, for example, already been observed in developing countries in Latin America and the Caribbean (Cruz and Milet 2017; López-Calva et al. 2010). Note that,

\footnotetext{
${ }^{1}$ The Gini coefficient has the value between 0 (perfect inequality) and 1 (perfect equality). The index form, the Gini index, is often reported in percentage value as in the World Development Indicators at the World Bank, and we follow that convention in the paper.

${ }^{2}$ World Bank (2011) and Bussolo et al. (2012).

${ }^{3}$ Freeman also argued that increased labor participation from China, India and the former Soviet bloc had not been matched by a commensurate increase in their contribution to the global capital stock, which would thus cause an increase in the returns to capital vis-à-vis to wages and push inequality up. Indeed, several authors (e.g. Atkinson 2015, Bourguignon 2015, Galbraigth 2012, Piketty 2014, and Stiglitz 2012) have called attention to the recent issue of rising capital share in total value added and to the concentration of income and wealth at the top of the distribution in many countries.

${ }^{4}$ While a truly 'global labor market' may not yet be in place, increased trade and financial integration, if not international migration, have intensified the interdependence of national labor markets. The question: "Are your wages set up in Beijing?" in the title of Freeman (1995) paper does not seem so rhetorical anymore.
} 
because of trade links, wages of skilled workers in high-income countries will also come under pressure even if their domestic supply will not be increasing. Signs of this pressure have also been already identified and attributed to trade by recent research (Autor et al. 2016).

An important factor may, however, have a counteracting role. As in the past, technological progress may be skill-biased and thus offset the supply (education) effect. Research has shown that in high-income countries like the United States, the premia for skilled workers remained high or even increased during expansions of the skilled labor supply (Acemoglu 1998; 2002).

Our analysis makes three contributions. First, it contributes to the debate about the evolution of global inequality. Several papers have looked at the past evolution of global income distribution (Bourguignon 2015, Bourguignon and Morrisson 2002; Milanovic 2002 and 2005; Atkinson and Brandolini 2010; Lakner and Milanovic 2016, among others) and a consensus is forming that distributional shifts have been large, especially between countries, and that a decline in global inequality may finally be in sight (Milanovic 2013). Some authors assert that a developing countries' middle class is emerging, but it is still vulnerable (Ravallion 2010). However, fewer studies adopt a forward-looking approach and consider what would happen if current trends continue. Hillebrand (2008) contends that unless "broad swaths of the developing world substantially improve their economic performance beyond that experienced in the last 25 years, the global income distribution will soon start to worsen again"; World Bank (2007) points out the strong presence of developing country citizens among the future global middle class, but also warns about distributional tensions within countries, and that a backlash against globalization may disrupt growth and income convergence. This paper directly contributes to this group of forward-looking studies by focusing on forces of the educational wave that shape future global supply and demand in the labor markets.

Second, this paper goes beyond a descriptive approach and explicitly models distributional dynamics. Expanding on earlier methodologies (Almeida dos Reis, Paes de Barros, 1991; Bourguignon et al. 2005), and combining two global economic models, the LINKAGE global general equilibrium model and the Global Income Distribution Dynamics (GIDD) microsimulation framework, we focus on the effects of educational attainment and demographic trends on distributional change. Apart from a few exceptions, Aziz et al. (2013), Dolls et al. (2019), and Edwards and Lange (2013) examined how demographic changes have contributed to inequality, these effects have been relatively neglected. Ahmed et al. (2016a) look only at the demographic dividend of the Africa region. In looking at the effect of changes in skill premia and sector mobility of labor on income inequality, our approach relaxes the assumption of distribution-neutral growth found in other studies (e.g., Ravallion 2013) to analyze global poverty.

Third, our approach brings together and harmonize at the global level a large data set from three sources. The first source is the population data and projections from the United Nations (UN 2015). The second is the revised household survey-based database of the GIDD, which covers 10.5 million sampled individuals from 127 countries. The third is the national accounts-based social accounting matrices for 129 regions/countries and 57 commodities linked by bilateral trade and external flows of the Global Trade Analysis Project (GTAP 2015). Apart from the methodological issues of reconciling national account and survey-based data (see Anand and Segal 2008), special attention went into redefining the skill disaggregation of the GTAP data by profession (such as managers, clerks, engineers, etc., which are difficult to project) to skill by education to match the microdata. With this large dataset, we extend and improve the LINKAGE and GIDD models. 
The remainder of this paper is organized as follows: Section 2 describes the past trends of educational demographics and set-up the analysis of how the forthcoming education wave may impact inequality through the labor markets. Section 3 presents the methodology and data. Section 4 shows simulation results along with robustness checks. The last section concludes.

\section{The engine of the education wave: education and demographic transitions by region}

The first step in the analysis of the impact of the education wave on global inequality is to quantify the forthcoming supply of skilled workers that originates in different parts of the world. Even by assuming that in the future there will be no additional investments in education, an expansion of the supply of skilled labor force can materialize through a 'pipeline effect' because of two key factors. The first is the intergenerational education gap, which is the difference in education attainments of the old cohorts that are exiting the labor market vis-à-vis the young entering cohorts. And the second is the intergenerational demographic gap, which is the difference in population size between the young and the old cohorts. Countries that in the past have boosted their investment in education and that have still high population growth have large intergenerational education and demographic gaps, and thus a large increase in their supply of skilled workers is expected in the future. Conversely, aging countries, where most of their population has already entered advanced secondary and tertiary education, will have old skilled workers replaced with similarly skilled young ones, and thus will not experience increases in the supply of skilled workers.

a) Europe and Central Asia, Latin America and the Caribbean, Sub-Saharan Africa and High Income

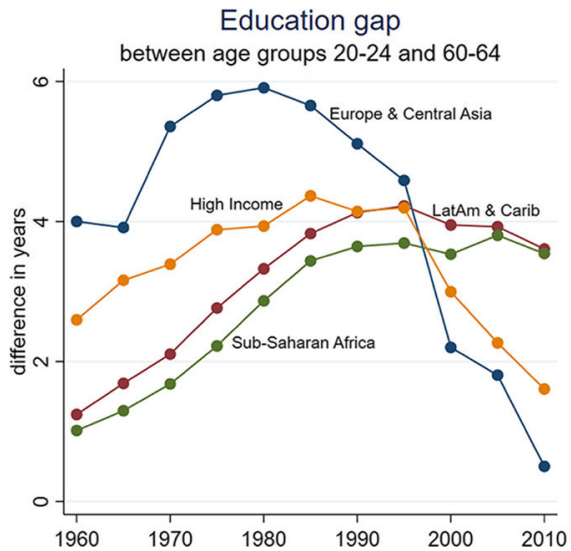

b) East Asia, Middle East and North Africa, South Asia

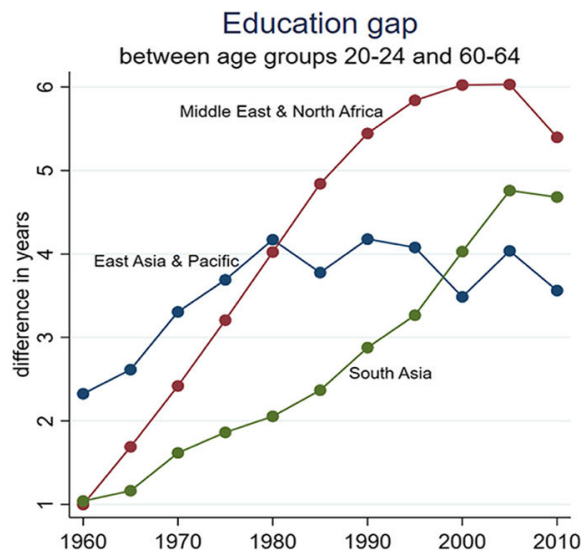

Fig. 1 Education transition by region. Source: Authors' elaboration based on Barro and Lee (2013). Note: Old cohort refers to the population between 60 and 64 years old. Young cohort refers to the population between 20 and 24 years old 
Figure 1 summarizes the educational transition by region from 1960 to 2010 . It shows the diverse trends in education investment across regions and the remarkable progress of developing countries. The average years of schooling for the young cohorts (20-24 years old) have improved when compared to the old cohorts (60-64 years old) in all developing regions except Eastern Europe and Central Asia. In the 1960s, young workers in Latin America and the Caribbean, Middle East and North Africa, South Asia, and SubSaharan Africa had about one additional year of education than their contemporary older workers. By 2010, this difference had increased to about four or more years of education, or the equivalent of almost a full cycle of secondary education. This trend is marginally different for countries in East Asia and the Pacific, which started with a slightly higher intergenerational gap (signaling that their investment in education had started even earlier) and progressed a bit more slowly.

By displaying regional and education cycle averages, Fig. 1 inevitably hides some variation across countries and different education levels. In Latin American and the Caribbean (LAC), for example, Bolivia started with an intergenerational education gap of 3.5 years and, by 2005, the gap rose to over 5 yrs; these gaps are quite higher than the regional average. Also, when focusing on the difference in the average number of years of tertiary education, an increase is still visible, but it is smaller, and the starting and end points are quite different from the overall education average. In Bolivia, the gap in tertiary education between young and old was initially close to zero, and the difference rose to only about a quarter of a year by 2005 . For Benin, in Sub-Saharan Africa (SSA), the difference in the average years of schooling for 25-29year-olds as compared to 60-64-year-olds was almost non-existent $(0.51$ years vs. 0.48 years) in 1980. By 2010, this difference rose to 1.5 years of schooling, remaining well below the regional average shown in Fig. $1 .^{5}$ This figure does not highlight that most of the gains in rising educational attainment in Africa are in primary and secondary education. There has been little progress in increasing the rates of tertiary education and beyond (except in a few countries, like Gabon).

Because China and India have been major drivers of recent declining global inequality as well as contributors of low skilled workers to the global labor force, a pressing question is whether future generations will still supply unskilled workers or will also add more skilled ones. The performance of East Asia and the Pacific, which to a large extent reflects the trends observed for China, shows that the average years of schooling for the young cohorts have improved significantly up to the 1980 s, with a leveling-off of the intergenerational gap after that. However, this leveling-off is at an intergenerational gap of about 4 yrs. Assuming conservatively that the educational attainment of future yet unborn young cohorts will not change, this gap will push up, just through the aging of the population, the overall education levels and the supply of skilled Chinese workers. India's educational attainment levels have been rising, although starting from a lower level than China's. The difference in years of schooling between young and older cohorts in India was 1.7 in 1980 and 3.0 in 2005 - with only a small increase in tertiary education, which looks weak in comparison to other middle-income countries. This observation is consistent with the large gap in average years of schooling observed in South Asia (SAR).

\footnotetext{
${ }^{5}$ The direction and magnitude of these differences are robust to wider cohort definitions.
} 
Two regions stand out because of their very different historical performance: the high- income countries group and Europe and Central Asia. Both regions start off in the 1960s with a higher (vis-à-vis developing regions) gap between young and old schooling achievements, due to their earlier investment in education. This gap increases in the first two or three decades, but then decreases and, towards the end of the period, the gap has almost disappeared. This trend should not be considered as lack of progress. On the contrary, once all young people achieve a desired (high) level of schooling, and this is maintained for all new cohorts, the difference in education between old and the young would disappear. However, an intergenerational education gap close to zero means that the region-wide average education will not increase. Some countries, notably the Russian Federation, are even experiencing a negative intergenerational gap in education: older cohorts tend to have more years of education than the young. Once the old workers retire, average education may go down. ${ }^{6}$

The impact of the intergenerational gap in education on the increase of the supply of skilled workers is magnified when the younger generations are larger in population size than the old ones. Similar to the previous figure, Fig. 2 shows the intergenerational demographic gap. This gap is expressed as the ratio of the population size of two age groups: the young, aged 20 to 24 and the old aged 60 to 64 . As before, there is a lot of heterogeneity across regions both in levels and trends. For advanced economies, and the Europe and Central Asia region the ratio at around two is low and slightly declining in the period 1960-2010. This fact means that new younger cohorts are still larger than older ones, but since the education level of the young is not much higher than that of the old, the average education is not expected to increase. ${ }^{7}$

In Latin America and the Caribbean, countries are beginning their aging process as the intergenerational demographic ratio shows a kind of inverted $U$ in Fig. 2, but this is compensated by the rapidly increasing educational gap. A similar pattern is observed for East Asia and the Pacific, with a decisively stronger aging trend. Figure 2 also shows that the other regions - the Middle East and North Africa, Sub-Saharan Africa, and South Asia - are in earlier phases of the demographic transition. Their increasing demographic ratios will boost the impact of the intergenerational education gap and push up the average education level strongly.

\footnotetext{
${ }^{6}$ The intergenerational education gaps described in the main text are based exclusively on comparing years of education across the young and old age groups. As such they do not consider the quality of education or the learning attained by individuals. Standardized tests, such as the PISA (OECD (Organization for Economic Co-operation and Development) 2016) test, measure learning of students and data on the scores of these tests are becoming available for more and more countries, but they are not included in this exercise. International comparisons show that individuals from high income countries tend to have higher test scores than those from poorer countries. However, as in the case of the quantity of education (years of schooling), developing countries are catching up. For example, during the period 2000-2012, the scores in the math subsection of the PISA test improved by about $12 \%$ in Latin American countries (covered by the PISA test), while the math score for high income countries decreased by about $1 \%$. Similarly, for the same period, scores for reading comprehension in East Asia and Pacific countries improved by $6 \%$ while it increased by just $1 \%$ in high income countries. Also, in quality terms one can talk of a developing countries-led education wave.
}

${ }^{7}$ Ahmed et al. (2016b) provides further description of different trends of demographic change across the word. 
a) Europe and Central Asia, Latin America and the Caribbean, Sub-Saharan Africa and High Income

Population by age groups

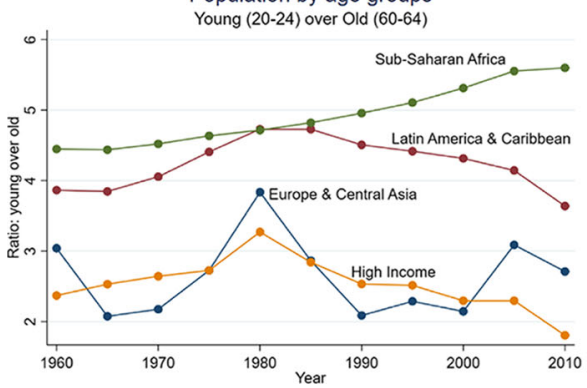

b) East Asia, Middle East and North Africa, South Asia

Fig. 2 Demographic transition by region. Source: Authors' elaboration based on Barro and Lee (2013)

As already mentioned above, the future evolution of the global labor force by skill level can be quantified by combining projections of population by age groups with some simple assumptions about the education of future young cohorts. The larger intergenerational education gap in developing countries, combined with the large size and growing pool of younger cohorts relative to the older ones in those countries, forms a strong 'pipeline effect', generating the key and significant dynamics of the education wave analyzed in this paper.

Relative to the global pool of skilled workers, the proportion of skilled workers in low- and middle-income (LMI) countries are projected to increase from $64.1 \%$ in 2012 to $70.4 \%$ in 2030 and continuing to $73.2 \%$ by 2050 ; it is expected to decline from $35.9 \%$ in 2012 to $29.6 \%$ by 2030 and $26.8 \%$ by 2050 in high-income countries. Moreover, the share of the population from LMI countries was approximately $83.6 \%$ in 2012. The share will steadily rise to $86.2 \%$ by 2030 and further to $87.7 \%$ by $2050 .^{8}$ Fig. 3 displays how the increasing in the number of workers with more than 9 yrs of schooling will be driven by developing countries. Although the simulations in the analysis are for about 20 years, from 2012 to 2030, the demographic

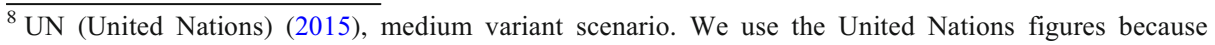
the demographic and labor figures for calibrating the LINKAGE and reweighting of households in the GIDD (see below) are from the World Development Indicators of the World Bank which, in turn, is based on the United Nations numbers. Our projections by age and education are consistent with the projections from the International Institute for Applied System Analysis (IIASA). Our focus in on the age/education evolution of the labor supply defined as the working age groups from age 15 to 64, while IIASA looks at the whole population (i.e. all age groups). A comparison of our labor projections to similar age groups in two of the published papers from IIASA authors show this consistency. For example, the population pyramids for all EU26 countries as shown in Figure 2 of Loichinger (2015) show a narrowing of the bands for the age groups 15 to 64 from 2010 to 2050 (i.e., a decline in absolute numbers) due to aging; accordingly, the bands for the age groups 65 and over are broadening (but which would be out of the labor force due to retirement or exit from our definition). Our case would include other OECD countries with the same overall results. Although the share of those with secondary and higher education remained high (and may be increasing), the absolute numbers are declining (clearly discernible from the two graphs in that paper). For developing countries, Samir et al. (2010) confirmed the rising numbers of labor with secondary or higher education for several countries.
} 


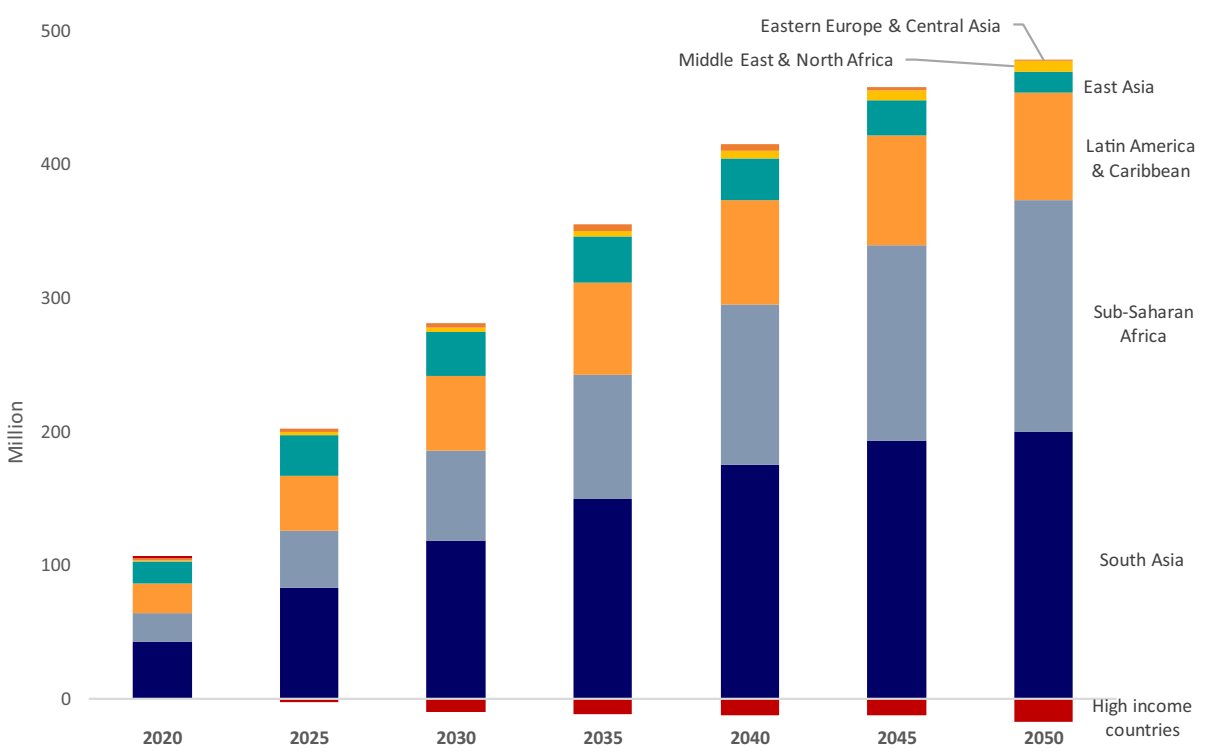

Fig. 3 Future sources of educated and skilled working-age population, new entrants w.r.t 2015. Source: Authors' projections. Notes: Skilled is defined as workers with more than 9 yrs of education. Projections are based on UN (2015) and education information from harmonized household and labor surveys from 117 countries

projections in the graph go to 2050 to show that the pattern realized by 2030 is stable and will continue well into the long-term future.

\section{Methodology and data}

The global distributional impacts of the education wave depend on changes in per capita incomes between countries and changes in inequality within countries. To capture the full - between and within countries - distributional change, one needs a framework that captures both convergences at the macro level (country averages) and the evolution of factor markets at the micro level (dispersion). To account for both effects, this paper uses the Global Income Distribution Dynamics (GIDD) microsimulation framework in combination with the LINKAGE global computable general equilibrium (CGE) model. ${ }^{9}$ Both tools have been developed at the World Bank and are described in detail by Bourguignon et al. 2008, Bussolo et al. 2010, and Van Der Mensbrugghe 2011). The next two sub-sections briefly describe their key features.

\footnotetext{
${ }^{9}$ The origin of dynamic microsimulation can be traced back to the $1950 \mathrm{~s}$ seminal work of Orcutt (1957) whose contributions aimed at overcoming the limitations of models available at that time. Orcutt observed that those earlier models could be used to predict the aggregate impact but could not describe the distributional impact of policy reforms nor the effects on inequality of long-term trends, such as demographic change. Data availability and modeling have significantly advanced since then, yet dynamic microsimulations remain the main tool to study distributional change and to provide the unique perspective of projecting samples of population forward in time.
} 


\subsection{The GIDD microsimulation model}

The ultimate focus of analysis is the evolution of the distribution of welfare in different scenarios. Starting from the base year " $t$ ", the income or expenditure $\left(Y_{i, t}\right)^{10}$ of each individual living in a household can be modeled as a function of: (i) household members' characteristics or assets (endowments) $(\boldsymbol{X})$, (ii) the market reward for those characteristics $(\boldsymbol{\beta})$, and (iii) the intensity in how those endowments are used as captured by a set of parameters $\lambda$ defining labor force participation and occupation status $(L \mid \lambda)$; and, finally, (iv) unobservable components $(\varepsilon)$ :

$$
Y_{i, t}=f\left(\boldsymbol{X}_{i, t}, \boldsymbol{\beta}_{t},\left(L_{i, t} \mid \lambda_{t}\right), \varepsilon_{i, t}\right)
$$

The income distribution $D$ for a population of $N$ individuals (or households) in the base year $t$ can be represented by a vector $\left\{Y_{1, t} \ldots Y_{i, t} \ldots Y_{N, t}\right\}$, where each $Y_{i t}$ can be defined as in (1) in terms of endowments, prices, labor status, and unobservables ${ }^{11}$ :

$$
D_{t}=\left\{Y_{1, t} \ldots Y_{N, t}\right\}=\left\{f\left(\boldsymbol{X}_{1, t}, \boldsymbol{\beta}_{t},\left(L_{1, t} \mid \boldsymbol{\lambda}_{t}\right), \varepsilon_{1, t}\right) \ldots f\left(\boldsymbol{X}_{N, t}, \boldsymbol{\beta}_{t},\left(L_{N, t} \mid \boldsymbol{\lambda}_{t}\right), \varepsilon_{N, t}\right)\right\}
$$

How does this distribution change dynamically, for example from year $t$ to year $t+k$ ? This framework allows distinguishing two sources that affect the dynamic change of distribution $D$, both of which are relevant for the assessment of the distributive impact of the education wave. The first source consists of the changes in either the parameters $\boldsymbol{\beta}$ or $\boldsymbol{\lambda}$, namely the market rewards to the characteristics (or assets) $\boldsymbol{X}$ and parameters affecting occupational decisions. This means, for example, that inequality for distribution $D$ can go down if the skill premia $\beta_{\text {skill }} / \beta_{\text {unskill }}$ is reduced; or if a change in labor demand in sectors with higher wages (a change in $\boldsymbol{\lambda}$ ) affects the decision to move to these sectors for some individuals working in sectors with lower wages. The second source of dynamic shift is represented by changes in the distribution of individual and household characteristics $(\boldsymbol{X})$. Alterations of the structure of the population in terms of age and education, and changes in the size and composition of households, will all affect the distribution of income of that population. ${ }^{12}$

Both sources of distributional change matter to the impact of the education wave. The GIDD allows generating a scenario that includes the education wave, which is then compared to a counterfactual where education achievements remain stable at the levels observed in $t$. Comparing the distributions $\widehat{D}_{t+k}^{\text {education_wave }}$ and $\widehat{D}_{t+k}^{\text {No_wave }}$ derived from the two scenarios in effect isolates the distributional impact of the education wave. Defining the contrasting values of endowments, prices, and labor status to build the two $\widehat{D}$ s can be quite challenging, especially when done globally for many countries. To do so, the functional form of Eq. (1) is defined in a simple fashion

\footnotetext{
${ }^{10}$ We use household consumption expenditure wherever available and income when consumption expenditure is not available (e.g., in many countries in Latin America and the Caribbean, LAC). The variables consumption and income are used interchangeably given the qualification. Clearly income dispersion will tend to be higher than consumption dispersion within countries; and having a uniform welfare variable for all countries would be better. However, this limitation affects all comparable studies of global income distribution (see for example World Bank 2016 or Lakner and Milanovic (2016). A list of countries and the corresponding specific welfare variable is found in table A3 in the Appendix 4.

${ }^{11}$ Note that here the representation of the income distribution is discrete. For a representation with continuous distributions, see Bourguignon et al. (2005).

12 These two sources of dynamic change are not independent one from the other and, in the real world, they are simultaneously determined. The problem of estimating and running a fully simultaneous microsimulation framework are discussed in more detail in Bourguignon and Bussolo (2013).
} 
using only variables available for all countries in the sample. In this paper, the right-hand side of Eq. (1) includes age, education endowments and sector of employment workers (country subscripts excluded for simplicity), so Eq. (1) can be re-written as:

$$
Y_{i, t}=\alpha_{t}+\beta_{1, t}\left(E_{i, t}^{S} S_{i, t}^{A}\right)+\beta_{2, t}\left(E_{i, t}^{S} S_{i, t}^{N A}\right)+\beta_{3, t}\left(E_{i, t}^{U S} S_{i, t}^{N A}\right)+\sum_{k=1}^{K} \gamma_{k, t} F_{k, t}+\varepsilon_{i, t}
$$

where $E^{s}$ and $E^{u s}$ are dummy variables identifying whether workers are skilled or unskilled, respectively; $S^{A}$ and $S^{N A}$ are dummy variables taking the value of 1 if the worker is employed in the agricultural sector or in the non-agricultural sector, respectively; $F_{k}$ captures the proportion of household members in each of the $k$ age cohorts. The $\beta$ s are rewards (prices) to education endowments conditional on the sector of employment, ${ }^{13}$ and the $\gamma \mathrm{s}$ are prices associated with the household composition. Finally, $\varepsilon$ includes all other income determinants not included in Eq. (3).

A counterfactual expression to (3) for year $t+k$ is:

$$
\begin{aligned}
\widehat{Y}_{i, t+k}=\widehat{\alpha}_{t+k} & +\widehat{\beta}_{1, t+k}\left(\widehat{E}_{i, t+k}^{S} \widehat{S}_{i, t+k}^{A}\left(\widehat{F}_{k, t+k}\right)\right)+\widehat{\beta}_{2, t+k}\left(\widehat{E}_{i, t+k}^{S} \widehat{S}_{i, t+k}^{N A}\left(\widehat{F}_{k, t+k}\right)\right) \\
& +\widehat{\beta}_{3, t+k}\left(\widehat{E}_{i, t+k}^{U S} \widehat{S}_{i, t+k}^{N A}\left(\widehat{F}_{k, t+k}\right)\right)+\sum_{k=1}^{K} \gamma_{k, t+k} \widehat{F}_{k, t+k}
\end{aligned}
$$

Compared with Eq. (3), where the demographic characteristics or assets, and the rewards to these assets are obtained directly from the household surveys data, these variables in Eq. (4) are micro-simulated. The microsimulation proceeds in two steps. ${ }^{14}$

In the first step, for each individual (by household and country), the variables $\widehat{E}, \widehat{S}$ and $\widehat{F}$ are projected using a reweighting procedure ${ }^{15}$ that ensures that the changes of the composition of the population in terms of (age and) education at the micro level are consistent with the aggregate changes derived from the age-education projections (or pipeline effect) described in section 2.2.

These aggregate changes, in turn, represent the shifts of the exogenous skilled and unskilled labor supplies in the LINKAGE model. With these inputs, the LINKAGE generates general equilibrium consistent returns to skilled and unskilled labor in the agriculture and nonagriculture segments of the market. In the second step, the changes in these returns with respect to the base year are used to micro-simulate the returns at the individual level. For example, if the percentage change in the return to skilled workers in the non-agriculture segment is, according to the CGE, equal to $\Delta_{t \rightarrow t+k}^{S, N A}$, then in Eq. (4) the micro-simulated return is obtained as:

$$
\widehat{\beta}_{2, t+k}=\beta_{2, t} \Delta_{t \rightarrow t+k}^{S, N A}
$$

\footnotetext{
${ }^{13}$ Note that unskilled workers employed in agriculture, i.e. when these dummies $S_{i, t}^{A} E_{i, t}^{U S}$ are equal to one, are the reference category, so they are excluded from the equation.

${ }^{14}$ A graphical summary of these steps and the links between the GIDD and the LINKAGE model is found in figure A1 of the Appendix 3.

${ }^{15}$ See Appendix 1 for details.
} 
When both the simulated characteristics and rewards are determined in these two steps, ${ }^{16}$ the new income for individual $i$ can be calculated from Eq. (4) ${ }^{17}$ and, when this is replicated for each individual, a new simulated distribution is generated. Note that the variables representing characteristics $(\widehat{E}, \widehat{S}, \widehat{F})$ and returns $(\widehat{\beta}, \widehat{\gamma})$ are also called Linkage Aggregate Variables (LAVs) as they are the variables that link the GIDD and LINKAGE models.

A couple of variants of Eq. (4) can be used to decompose the full change in the distribution. A first variant consists of using Eq. (4) with only new micro-simulated characteristics but with unchanged returns. Formally, this variant can be written as:

$$
\begin{aligned}
\widehat{Y}_{i, t+k}^{\prime}= & \widehat{\alpha}_{t}+\beta_{1, t}\left(\widehat{E}_{i, t+k}^{S} \widehat{S}_{i, t+k}^{A}\left(\widehat{F}_{k, t+k}\right)\right)+\beta_{2, t}\left(\widehat{E}_{i, t+k}^{S}{\widehat{S^{\prime}}}_{i, t+k}^{N A}\left(\widehat{F}_{k, t+k}\right)\right) \\
& +\beta_{3, t}\left(\widehat{E}_{i, t+k}^{U S}{\widehat{S^{\prime}}}_{i, t+k}^{N A}\left(\widehat{F}_{k, t+k}\right)\right)+\sum_{k=1}^{K} \gamma_{k, t} \widehat{F}_{k, t+k}+\varepsilon_{i, t+k}
\end{aligned}
$$

This new Eq. (4') represents a 'partial' change in the incomes, and thus in the distribution, that is due to a pure demographic (or quantity) education effect. Other characteristics and rewards have not been changed yet. ${ }^{18}$ Likewise, a second variant of Eq. (4), where only the rewards are modified but not the characteristics, can be set up to represent the shift in distribution exclusively due to changes in rewards. A brief description of the determination of these rewards completes this methodology section.

\subsection{The LINKAGE general equilibrium model}

GIDD simulates the behavior of consumers and workers, but it does not have a market-clearing mechanism because it does not include the suppliers of goods and demanders of labor, i.e., the firms. This creates the need for having a source of information on macro variables such as the level of wages, the change in relative goods prices, overall income growth. The solution adopted in this paper is to link the GIDD to LINKAGE. LINKAGE is a multi-sectoral, multicountry, and multi-agent dynamic recursive CGE model. At its core, it is essentially a neoclassical growth model, with aggregate growth predicated on assumptions regarding the

\footnotetext{
${ }^{16}$ Characteristics and rewards should be jointly determined. For example, the decision to pursue further education depends on the return and cost of education, which in turn depend on how many people pursue education and enter the market for educated workers. However, this simultaneity is not implemented in the GIDD, nor for most microsimulation models. For a detailed discussion of these issues see Bourguignon and Bussolo (2013).

${ }^{17}$ Note that the intercept needs to be micro-simulated as well. In fact, this is modified so that the after all the other changes are applied, the per capita economy-wide growth can be targeted. In other words, the simulated characteristics and returns change the shape of the income distribution and its position (or its mean). However, the complete effect of income growth is not captured by just these changes. For example, accumulation of capital/ land and other factors and changes in their returns are not considered in this version of the GIDD for lack of good data in the surveys. Thus, the intercepts are shifted equally for all individuals (i.e. a distributionally neutral shift) to ensure consistency between the per capita income growth simulated in the LINKAGE and the change of the mean in the GIDD microdata. This is likely to cause underestimation of changes of inequality within countries, but it does not affect inequality across countries.

${ }^{18}$ Note that the constraints of the reweighting procedure are in terms of (age cohorts and) education levels of the population in year $t+k$, and not in terms of sectoral employment. However, because skilled workers may initially be more concentrated in the non-agricultural sectors, increasing the weight of skilled workers in the total population generates also an increase in the share of non-agricultural employment. This is why, in equation (4'), sectoral dummies are labelled as $\widehat{S}_{i, t+k}^{\prime A} \widehat{S}_{i, t+k}^{\prime N A}$ with a prime (') sign. These do not necessarily represent the final sectoral employment which is determined by the CGE model.
} 
growth of the labor force by skill level, savings/investment decisions (and therefore capital accumulation) and productivity. ${ }^{19}$

For each year of the simulation, production is modeled using nested CES (Constant Elasticity of Substitution) functions that combine at various levels, with different substitution elasticities, intermediates, and primary factors. ${ }^{20}$ Households' consumption demand is derived from the maximization of household-specific utility function following the Linear Expenditure System (LES). International trade is modeled assuming imperfect substitution among goods originating in different geographical areas. Imports demand results from a CES aggregation function of domestic and imported goods. Export supply is symmetrically modeled as a Constant Elasticity of Transformation (CET) function. Producers decide to allocate their output to domestic or foreign markets responding to relative prices. The assumptions of imperfect substitution and imperfect transformability grant a certain degree of autonomy of domestic prices with respect to foreign prices and prevent the model from generating corner solutions. ${ }^{21}$

The labor market specification is a key element of LINKAGE and an important driver of the distributional results. Therefore, its specification calls for some clarification and justification. Two types of labor are distinguished, skilled and unskilled. These categories are considered imperfectly substitutable inputs in the production process. Moreover, some degree of factor market segmentation is assumed: skilled workers are perfectly mobile across sectors, whereas, in developing countries, the labor market for the unskilled is divided into agriculture and nonagriculture segments. The labor market segmentation by skill level has become a standard assumption in CGE modeling. The imperfect substitution in the production process for workers with different skills is likely to persist for the medium-term time horizon, as unskilled workers cannot be 'transformed' into skilled ones, even with increased on-the-job training.

The assumption that the market for unskilled labor is further segmented into agricultural and non-agricultural activities is more controversial. However, econometric analysis indicates that a gap in remunerations between these two segments remains even after controlling for education, gender, experience, and other variables, including cost of living differentials (between rural areas, where agricultural activities are predominantly located, and urban ones). Some barriers to

\footnotetext{
${ }^{19}$ The model is complex, and we present only a brief description. Nonetheless, a detailed description and list of equations of the model are available in Van Der Mensbrugghe 2011 and its weblink- http://siteresources. worldbank.org/INTPROSPECTS/Resources/334934-1314986341738/TechRef7.1_01Mar2011.pdf. The version of the LINKAGE model used here has a 2011 base year and relies on the Global Trade Analysis Project (GTAP) Database Version 9 (www.gtap.org). See table A3 of Appendix 4 for country and regional mapping.

${ }^{20}$ At the top of the nest, a value-added bundle combines with an intermediate-inputs bundle under the Leontief technology assumption. Each intermediate input is, in turn, a bundle of domestically produced and imported varieties, combined using the Armington assumption of imperfect substitutability. The value-added bundle is made up of capital and skilled labor under one nest, and that bundle, in turn, is slightly substitutable with unskilled labor. The choice of the elasticity values in the production function often depends on the structure of the model and the level of aggregation. We find that an elasticity of 2 between capital and skilled labor and the same value between unskilled labor and the bundle of capital and skilled labor works well for the level of disaggregation in this paper and from previous testing and applications by authors (such as Ahmed et al. 2016a, 2016b, 2016c, Devarajan et al. 2015, and Bourguignon et al. 2008). A lower elasticity would be appropriate, the more aggregated the structure of the economy and its factor markets. At the extreme, when the economy is one sector with one labor and capital (a Solow growth model), the elasticity between labor and capital traditionally takes the value of one (a Cobb-Douglas function in Solow 1956) or less than one in more recent findings (e.g., LeónLedesma et al. 2010 or de la Granville 2017). The same tendency appears to be the case with trade-related elasticities and the level of commodity specificity (e.g., Hillberry and Hummels 2013; Devarajan et al. 1999).

${ }^{21}$ However, even if these assumptions attenuate factor prices equalization when countries trade with each other, trade is still an important channel through which factor prices are influenced (during the scenarios, when factor abundance changes). And this allows us to talk about a global labor market.
} 
mobility - land ownership providing economic security to farmers, specificity to human capital acquired in agriculture, or others - must exist and hinder equalization of wages across the two segments. In the model, this segmentation is implemented with some flexibility. Using a HarrisTodaro specification, a certain number of unskilled workers migrate from one segment to the other in response to changes in the wage differentials across the segments. ${ }^{22}$

This rich set-up allows capturing the changes in wages for different types of workers. And since skilled-unskilled and rural-urban (or, more precisely, agriculture - non-agriculture) wage gaps represent important drivers of inequality, this set-up enables to model changes in the income distribution of each economy.

Capital accumulation, labor expansion, and productivity changes determine the growth dynamics in the model. In each period, capital stock is equal to the depreciated capital stock from the previous period augmented with the investment. Investment is driven by savings, which, in turn, depend on per capita income growth and the population youth and elderly dependency ratios. In contrast to national savings, foreign savings are exogenous, and their time paths are obtained by assuming that the initial current account imbalances will to tend to zero in the long run.

The evolution of the labor force is in line with the change of working-age population. ${ }^{23}$ As described above, the growth of the supplies of skilled and unskilled workers is consistent with this overall growth of the labor force and with the pipeline effect.

The model assumes heterogeneity of productivity trends across sectors. Productivity in agriculture is assumed to be factor-neutral and exogenous and is set to estimates from empirical studies (e.g., Martin and Mitra 1999). Productivity in manufacturing and services is labor-augmenting; it is skill-neutral but sector-biased. In the case of agriculture, productivity growth averages $2.5 \%$ per annum for all countries. In manufacturing and services, changes in productivity are country-specific and based on past trends. Following the broad findings of Bosworth and Collins (2003), productivity growth in manufacturing is assumed to grow about three percentage points faster than in services. ${ }^{24}$

This model calculates wages of skilled and unskilled workers by combining firms' demand for labor with the aggregate change in supplies of these two types of workers. In addition to the changes in rewards, the computable general equilibrium model also calculates the overall economic growth and sectoral reallocation of labor. ${ }^{25}$ As already described above, changes of

\footnotetext{
${ }^{22}$ We do not distinguish agricultural sector and rural regions, which may neglect the presence of rural non-farm activities. See, for example, Reardon et al. (2007).

${ }^{23}$ This means that participation rates are constant. This is a conservative assumption given that the overall labor force participation rates are likely to increase as more women enter the labor force in developing countries or due to the changes in the retirement age in high income countries. The United Nation population projections are disaggregated by age groups and gender. They include net migrations per 1000 people by country/region. We do not provide alternative migration scenarios, which can be complex and beyond the scope of this paper. However, migration can certainly be handled by the methodology, see for example, Ahmed et al. (2016b).

${ }^{24}$ The dynamic calibration allows the model to reproduce, in its baseline scenario, GDP growth rate trends that are in line with available long-term projections such as, for example, the growth projections under the Shared Socio-Economic Pathway Scenario 2 of Dellink et al. (2017). In fact, during the dynamic calibration the model targets these exogenous growth rates of GDP by endogenously determining the labor augmenting productivity factor described in the text. In the counterfactual scenarios, the real GDP growth rate is endogenized, and the uniform productivity variable is exogenized, and simulated to grow at the rate determined in the baseline scenario. The real growth rate can thus change depending on the other shocks considered in the scenario.

${ }^{25}$ In the GIDD microsimulations, workers move across sectors to achieve the proportions of employment in agriculture and non-agriculture calculated by the CGE model. Note that these inter-sectoral movements are net of the sectoral shifts already generated by the reweighting procedure. The microsimulation procedure to select which specific worker moves is based on a probabilistic model described in detail in Bussolo et al. (2010).
} 
these variables - the Linkage Aggregate Variables (LAVs) - are used as inputs in the final step of the microsimulation.

\subsection{The micro data underlying the models and the analysis}

The modeling framework just described uses a combination of data sets from three different sources. First, we use population projections from the UN (2015). Second, we use Social Accounting Matrices from the GTAP version 8 with 2011 as the base year for the CGE scenarios. Third, we use the GIDD database, which is composed of harmonized household surveys for a large number of countries.

The GIDD dataset is derived from household surveys harmonized by the World Bank. ${ }^{26}$ It provides a cross section of surveys using 2011 as a base year. ${ }^{27}$ The sample covers 10.5 million individuals in 127 countries, constituting $83.4 \%$ of the global GDP and $86.3 \%$ of the global population $^{28}$ (see Table 1). The coverage of the data in GIDD is also large for most specific regions, both in terms of population and GDP.

From the household surveys, we extract information on individuals' age, employment status, sector of activity, years of schooling, and wage as the starting points to project the population growth by school attainment and the sectoral wage bill database (Cruz et al. 2017). These pieces of information feed into the LINKAGE model to establish consistency between the skill definition and volume of workers between the CGE model and the microsimulations.

Table 2 shows, in the grey background panel, the share of workers by broad sectors (agriculture and non-agriculture) and skill level for 2012. The tabulation indicates that the share of skilled workers is much larger in high-income countries and the region of Europe \& Central Asia (ECA). The three regions of East Asia \& Pacific (EAP), South Asia (SAS), and Sub-Saharan Africa (SSA) together had approximately $96 \%$ of the people living below the poverty line in 2015 . In all of these regions, $30 \%$ or more of the paid workers were unskilled working in agriculture.

This table also shows, in the right panel, that there are significant differences in the average wages of workers (conditional on their level of skill) between sectors and regions. An average unskilled worker in non-agriculture in high-income countries has a wage that is significantly higher than an average skilled worker in a non-high-income economy. Also, skill premia in the wages by sector are sharply characterized. ${ }^{29}$

An important channel through which changes in the composition of labor supply may affect income inequality and income distribution, in the long run, is the movement of workers across different categories delineated by the four segments: agriculture, non-agriculture, skilled workers, and unskilled workers. As the table shows, the relative size of these four segments starts from quite different initial points across the regions of the world. The other key channel

\footnotetext{
${ }^{26}$ The data include household surveys harmonized by the Poverty Group Global Practice of the World Bank and the International Income Distribution Database (I2D2). The I2D2 is a World Bank project to collate, harmonize and make accessible comparable information from household surveys held by the World Bank, for poverty, inequality, education, demographics, and labor market analysis. For further details on I2D2, see Montenegro and Maximilian (2009).

${ }^{27}$ For each country, the closest survey to 2011 has been chosen to be consistent with the database used in the LINKAGE model (Global Trade Analysis database v.8). From this dataset we derived the GIDD Sectoral Wage Bill database (Cruz, Go, and Osório-Rodarte 2017).

${ }^{28}$ If Japan and Switzerland are included with aggregated information generated from household surveys, using the Luxemburg Income Study data set, the GDP coverage increases to approximately $93 \%$.

${ }^{29}$ The wages for skilled workers in agriculture are higher than the wages for unskilled workers in the same sector. The same happens in non-agriculture activities.
} 
Table 1 GIDD database coverage

\begin{tabular}{|c|c|c|c|c|c|}
\hline \multirow[t]{2}{*}{ Region } & \multicolumn{2}{|c|}{ GDP PPP\$, B } & \multicolumn{2}{|c|}{ Population, M } & \multirow[t]{2}{*}{ Microdata obs. } \\
\hline & Total & $\%$ & Total & $\%$ & \\
\hline Low and middle-income countries & $13,781.5$ & 90.8 & 5788.3 & 87.8 & $5,320,925$ \\
\hline East Asia \& Pacific & 5698.5 & 96.5 & 1991.8 & 94.6 & 918,891 \\
\hline Europe \& Central Asia & 1287.5 & 80.9 & 269.8 & 67.0 & 347,714 \\
\hline Latin America \& Caribbean & 3379.2 & 98.2 & 585.6 & 98.0 & $1,472,436$ \\
\hline Middle East \& North Africa & 843.6 & 19.5 & 344.1 & 19.4 & 70,402 \\
\hline South Asia & 1703.2 & 99.3 & 1675.0 & 98.2 & 782,726 \\
\hline Sub-Saharan Africa & 869.6 & 92.3 & 922.1 & 79.4 & $1,728,756$ \\
\hline High-income countries & $40,979.1$ & 81.0 & 1277.2 & 79.6 & $5,134,448$ \\
\hline World & $54,760.6$ & 83.4 & 7065.5 & 86.3 & $10,455,373$ \\
\hline
\end{tabular}

Source: Authors' elaboration using available data from GIDD-dataset

is represented by shifts relative wages. The combined quantity and price changes are the key determinants of the distributional results of the education wave to which we now turn.

\section{Results}

\subsection{The scenarios}

The "education wave" scenario is our baseline scenario. It includes the substantial changes in the global labor market due to the continuation of the education and demographic transitions

Table 2 Workers and Wages by region, sector of activity and skill level

\begin{tabular}{|c|c|c|c|c|c|c|c|c|c|c|c|c|}
\hline & \multicolumn{5}{|c|}{ Workers } & \multicolumn{7}{|c|}{ Wages } \\
\hline & \multicolumn{4}{|c|}{ Shares } & \multirow{3}{*}{$\begin{array}{l}\# \\
10^{\wedge} 6 \\
\text { All }\end{array}$} & \multicolumn{4}{|c|}{ Monthly in US\$(PPP) } & \multicolumn{3}{|c|}{ Skill Wage Premia } \\
\hline & \multicolumn{2}{|c|}{ Agriculture } & \multicolumn{2}{|c|}{ Non-Agri } & & \multicolumn{2}{|c|}{ Agriculture } & \multicolumn{2}{|c|}{ Non-Agri } & \multirow[b]{2}{*}{ Agri } & \multirow[b]{2}{*}{ Non-Agri } & \multirow[b]{2}{*}{ Total } \\
\hline & Skill & Unsk & Skill & Unsk & & Skill & Unsk & Skill & Unsk & & & \\
\hline $\begin{array}{l}\text { East Asia } \\
\qquad \& \text { Pacific }\end{array}$ & 3 & 29 & 23 & 45 & 997 & 244 & 152 & 409 & 281 & 1.6 & 1.5 & 1.5 \\
\hline $\begin{array}{l}\text { Europe \& } \\
\quad \text { Central Asia }\end{array}$ & 5 & 7 & 66 & 22 & 69 & 282 & 281 & 523 & 380 & 1 & 1.4 & 1.4 \\
\hline $\begin{array}{l}\text { Latin America } \\
\text { \& Caribbean }\end{array}$ & 2 & 10 & 52 & 37 & 253 & 492 & 223 & 786 & 359 & 2.2 & 2.2 & 2.4 \\
\hline $\begin{array}{l}\text { Middle East \& } \\
\text { North Africa }\end{array}$ & 0 & 19 & 19 & 62 & 13 & 296 & 205 & 293 & 257 & 1.4 & 1.1 & 1.2 \\
\hline South Asia & 6 & 36 & 24 & 33 & 475 & 124 & 93 & 230 & 108 & 1.3 & 2.1 & 2.1 \\
\hline $\begin{array}{l}\text { Sub-Saharan } \\
\text { Africa }\end{array}$ & 3 & 34 & 22 & 41 & 182 & 155 & 72 & 327 & 138 & 2.2 & 2.4 & 2.9 \\
\hline $\begin{array}{l}\text { High-income } \\
\text { countries }\end{array}$ & 2 & 1 & 87 & 10 & 465 & 1129 & 685 & 1849 & 1037 & 1.6 & 1.8 & 1.8 \\
\hline World & 3 & 23 & 40 & 34 & 2454 & 289 & 114 & 987 & 281 & 2.5 & 3.5 & 4 \\
\hline
\end{tabular}

Source: Authors' elaboration based on GIDD-dataset. Note: Wage skill premia are calculated by dividing the average wages of skilled to unskilled. This table aggregates workers across countries and regions 
described in sections 2.2. At the outset, around 2012, one skilled worker from a high-income (OECD) country is competing with two skilled workers from developing countries. In less than a generation, by 2030, that ratio will be 1 to 3, confirming that the global pool of skilled workers will originate mostly in developing countries. This shift will likely have repercussions on the global distribution of income as it will transform once again, as the 'great doubling' did in the first wave, the world's labor market.

The education wave will also affect local distribution within countries, with impacts varying from country to country. Fig. 4 illustrates the geographic dispersion of the education wave with the growth rates of skilled labor (y-axis) against those for unskilled labor (x-axis). Most of the dots, which represent countries or regions, are above the 45-degree line, meaning that the supply of skilled workers will grow faster than that of unskilled workers.

Even so, there is heterogeneity across countries. First, the growth rate of unskilled workers is often negative in 'older' countries and regions. Compare, for example, the reduction rates of $30 \%$ or $15 \%$ for unskilled populations in Europe or China, versus the expansion rates of 53\% for Nigeria, or $65 \%$ for the Sub-Saharan region. Second, very few countries or regions experience growth rates that are similar for the two groups of workers (that is, no education wave): the only dots (in the figure) that are close to the 45-degree line are those for the US, Russian Federation, and Sub-Saharan Africa. For most of the other countries, however, the differences can be quite large. In Turkey, the gap between the rates of expansion of skilled and unskilled populations is of almost 50 percentage points. For Brazil and Nigeria, the gap is close to 40 percentage points, for Indonesia, India, China is between 25 and 33 percentage points. The Russian Federation is the only country found below the 45-degree line, albeit close to it. In this country, older generations tend to have more education than younger ones. This fact, combined with an aging population, generates a rate of reduction of skilled workers slightly higher than that of unskilled workers, resulting in a (negative) gap of 3 percentage points.

These changes in the labor supply of different education levels constitute the exogenous education wave of our baseline scenario. These changes are conservative, as many countries will likely do better since they will boost their education investments. By doing that,

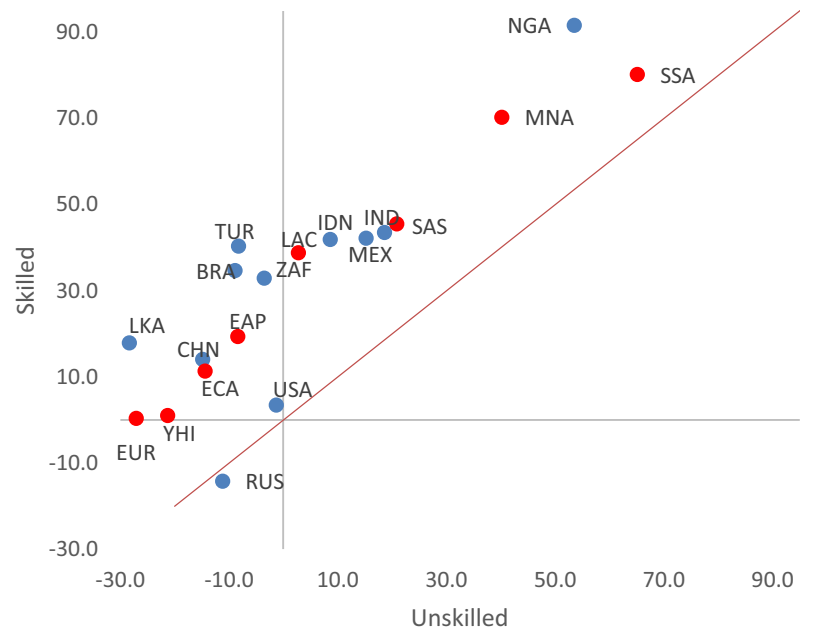

Fig. 4 Growth rates of labor by skill, sector and country/region. Source: Authors' calculations based on GIDD projections. Note: the growth rates are expressed as the cumulative growth for the period 2030-2012. The red dots represent regions; the blue dots are individual countries 
educational attainment among the future young generations will be even higher than the current young generations. The education wave, if such improvement were accounted for, would be even larger than what is currently defined in the baseline.

Table 3 summarizes the four simulations used for this analysis: two main scenarios (the education wave and no education wave), and two sensitivity tests. Against the baseline (education wave), a 'no wave' is set up as the main counterfactual simulation, which is a what-if scenario in which the education trend of the baseline is removed. Two additional sensitivity tests aim to shed some light on the potential consequences for the results specifically for the skill premia - of changes in the technology of production.

Since the baseline and what-if counterfactual simulations contain similar underlying economic projections and parameters, their differences minimize the effects of common assumptions and isolate the effects of the critical factor of each counterfactual simulation. The simulation period is for 20 years, from 2012 to 2030, which makes it more comparable to the first wave. This time horizon also makes the analysis more conservative because it will not cover the full impact of the education wave beyond 2030.

\subsection{Results at the macro level: growth differentials and wage premia}

Most long-term growth projections (see Dellink et al. 2017) assume that developing countries will grow faster than high income countries. Demographic (increasing share of working- age population) and technological (productivity catching up) factors mainly justify this differential. The growth differential vis-à-vis high-income countries is quite pronounced for East Asia and the Pacific region as well as for South Asia region. ${ }^{30}$ These differentials bring about convergence in incomes per capita and are a key driver for the reduction of the between-country component of global inequality.

Is the education wave contributing to the reduction of global inequality from the perspective of this between-country convergence? The answer is yes, but it does not seem much in the aggregate, as shown in Fig. 5. The contribution of the education wave - vis-à-vis a scenario where skilled and unskilled workers grow at the same rate - comes exclusively from the higher productivity of skilled workers who are becoming more abundant in the wave scenario. However, other drivers of growth and convergence, namely the catching up of productivity and supplies of other factors (land and capital), do not change across simulations. For these reasons, the education wave boosts convergence by, at best, about one percentage point in East Asia and the Pacific and Latin America and the Caribbean regions, but its impact is more limited in other regions. The convergence differentials should be considered a lower bound, given that more abundant skilled workers are likely to generate externalities and an additional productivity uptick that is not simulated here. In addition, we have very conservative education projections and are looking at a relatively short period of time to fully capture the effects of the education wave.

One final point on the regional aggregate growth rates. The education wave, as discussed above, is a scenario where the growth of the global pool of skilled workers is almost entirely due to the expansion of education in developing countries. Indeed, by 2030 for all developing

\footnotetext{
${ }^{30}$ During the period 2012-2030 in the baseline scenario, the annual average growth rate of income per capita by geographical region are as follows: $8.7 \%$ in East Asia and Pacific, 3.1 in Europe and Central Asia, 3.3 in Latin America and the Caribbean, 2.6 in Middle East and North Africa, 4.4 in South Asia, 2.7 in Sub-Saharan Africa, and 2.7 for the high income countries.
} 
Table 3 CGE baseline and counterfactual scenarios

\begin{tabular}{|c|c|c|}
\hline Scenario & Key features & Purpose \\
\hline $\begin{array}{l}\text { Baseline - the education } \\
\text { wave scenario }\end{array}$ & $\begin{array}{l}\text { Population projections from UN (2015) } \\
\text { medium-fertility variant scenario; } \\
\text { economic growth projections from } \\
\text { World Bank (2015); the share of } \\
\text { skilled workers grows assuming } \\
\text { constant education attainment rates. }\end{array}$ & $\begin{array}{l}\text { Establish a business-as-usual } \\
\text { or reference case for comparison } \\
\text { with counterfactual scenarios. }\end{array}$ \\
\hline No education wave scenario & $\begin{array}{l}\text { Same as baseline except for the fact } \\
\text { there are no changes in the share of } \\
\text { skilled workers. }\end{array}$ & $\begin{array}{l}\text { Provide a counterfactual scenario } \\
\text { without the "education wave." }\end{array}$ \\
\hline $\begin{array}{l}\text { Higher elasticity of } \\
\text { substitution between } \\
\text { skilled labor and capital }\end{array}$ & $\begin{array}{l}\text { The baseline plus a higher elasticity of } \\
\text { substitution of } 3 \text { (previously } 2 \text { ) } \\
\text { between skilled labor and capital. }\end{array}$ & $\begin{array}{l}\text { This scenario tests the sensitivity of the } \\
\text { results for changes in the } \\
\text { substitutability between skilled labor } \\
\text { and capital to mimic the } \\
\text { consequence of a biased } \\
\text { technological change }\end{array}$ \\
\hline $\begin{array}{l}\text { Alternative nesting structure } \\
\text { of labor and capital }\end{array}$ & $\begin{array}{l}\text { The baseline with an alternative nesting } \\
\text { structure. Skilled and unskilled labor } \\
\text { are substitutable with each other, and } \\
\text { together also substitutable with } \\
\text { capital. We use elasticities of } \\
\text { substitution of } 2 \text { for the } \\
\text { two relevant nests. }\end{array}$ & $\begin{array}{l}\text { This scenario tests the sensitivity } \\
\text { of the results for technological } \\
\text { changes that may affect the } \\
\text { substitutability between skilled and } \\
\text { unskilled workers. }\end{array}$ \\
\hline
\end{tabular}

Source: Authors' elaboration

countries incomes per capita are higher in the wave versus than in the no-wave scenario, while for the rich countries incomes are unchanged. The stagnation of incomes in high income countries may increase the backlash against globalization and exacerbate the negative effects of inequality within these countries. As discussed below, our analysis suggests that middleincome classes of high-income countries will likely continue experiencing some pressure.

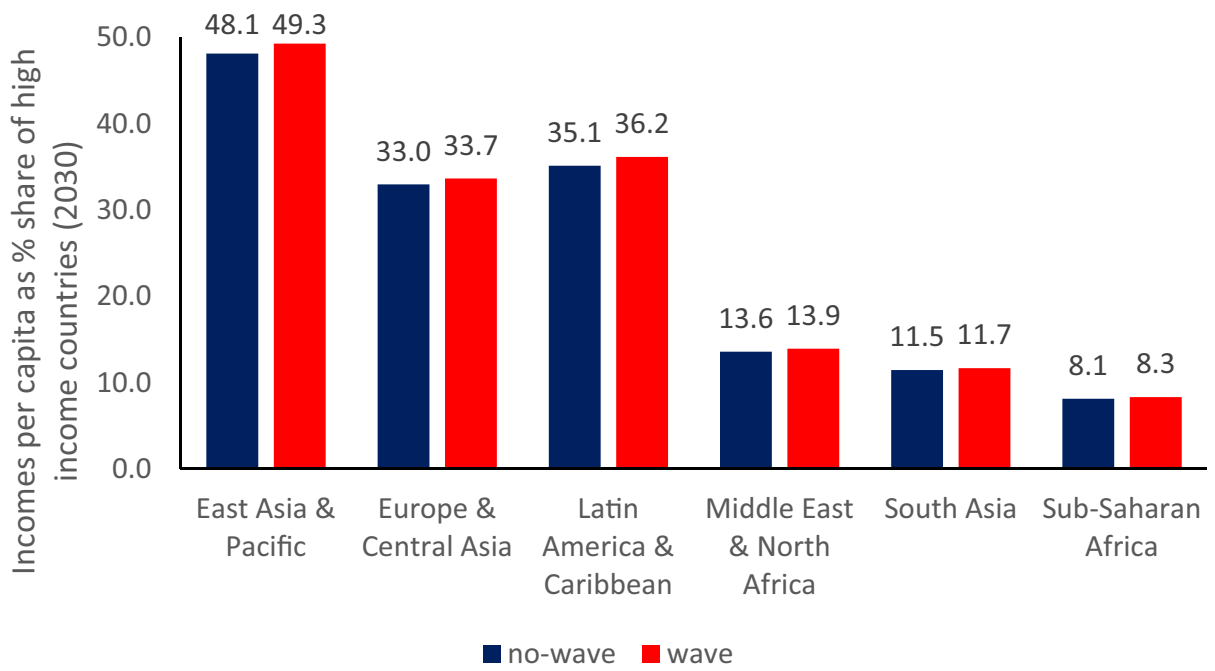

Fig. 5 Incomes convergence - education versus no education wave. Source: CGE and GIDD simulations results 
Changes in the skill and sector premium of wages are the other crucial macroeconomic results of the simulations that affect global inequality through their effects on incomes dispersion within each country.

In the education wave scenario, countries with the highest increases in the relative supply of skilled versus unskilled workers in 2030 vis-à-vis 2012 will experience the largest reductions of the skill premium (Fig. 6). A simple regression line that relates the relative size of the skill premium against the relative supply of skilled labor has a negative slope. The causality in this framework runs from the changes in the quantities of workers to the changes in the wages because all labor supplies are exogenous. Turkey, Brazil, and South Africa are amongst the countries with the largest drops in the skill premium, and the highest increases in the relative supply of skilled workers. In Turkey, the skill premium by 2030 is reduced by $20 \%$ of what it was in 2012. At the opposite end, the premium increases by about $5 \%$ in the Russian Federation, a country where the relative supply of skilled workers decreases (see Fig. 4).

Changes in the urban premium of wages for unskilled workers also affect distributional shifts. As explained in section 3.2, this premium occurs because the market of unskilled workers in developing countries is segmented, and workers can migrate from rural-agriculture activities to urban-non-agriculture ones only imperfectly. The urban premium and the allocation of unskilled workers across the two segments are thus endogenously determined by the differential demands for unskilled workers in the rural and urban segments and their interaction with migration.

As each country urbanizes, production and income growth, as well as the allocation of unskilled workers, will all shift towards non-agricultural sectors. ${ }^{31}$ Even so, the urban premium for unskilled workers will still tend to go down due to the relative intensities of factor use in the production function across sectors. That is, agriculture, which is more intensive in the unskilled factor, will release many more unskilled workers than those needs by the expanding non-agriculture sectors, resulting in a relative oversupply of unskilled workers, driving down the premium for unskilled workers in the urban sector. Fig. 7 depicts the reduction of the urban premium of wages in 2030 relative to 2012 against the relative sector supply of unskilled workers.

\subsection{Results at the micro level}

\subsubsection{Between- and within-country evolution of inequality}

The microsimulation results confirm that the world will become more equal by 2030 as it becomes more educated (Table 4). The (individual-based) Gini index falls from 65.8 in 2012 to 62.6 in 2030, while the Theil index is reduced from 90.7 to 76.6. Compared to recent patterns, these results suggest a continuation of the reduction in global inequality. In a 20-year interval from 1988 to 2008, during the great doubling of the global labor force, global inequality decreased by about 2 Gini points (Lakner and Milanovic 2016). Our education wave scenario shows a comparable reduction of 3.2 Gini points, with the global Gini index falling during the period 2012 to 2030. The Theil index also suggests a similar reduction of close to 14 percentage points by 2030 .

\footnotetext{
${ }^{31}$ Demand for workers by the different sectors is in line with firms' production plans which in turn depend on consumers, export and other final demands. Due to income growth - and an elasticity with respect to income above one of consumption of non-agricultural goods - demand for manufacturing goods and services (i.e. demand for non-agricultural goods) increases more rapidly than demand for agricultural commodities. This shift of demand is transmitted to production, and consequently demand for labor in non-agricultural sectors increases faster than that in agriculture.
} 


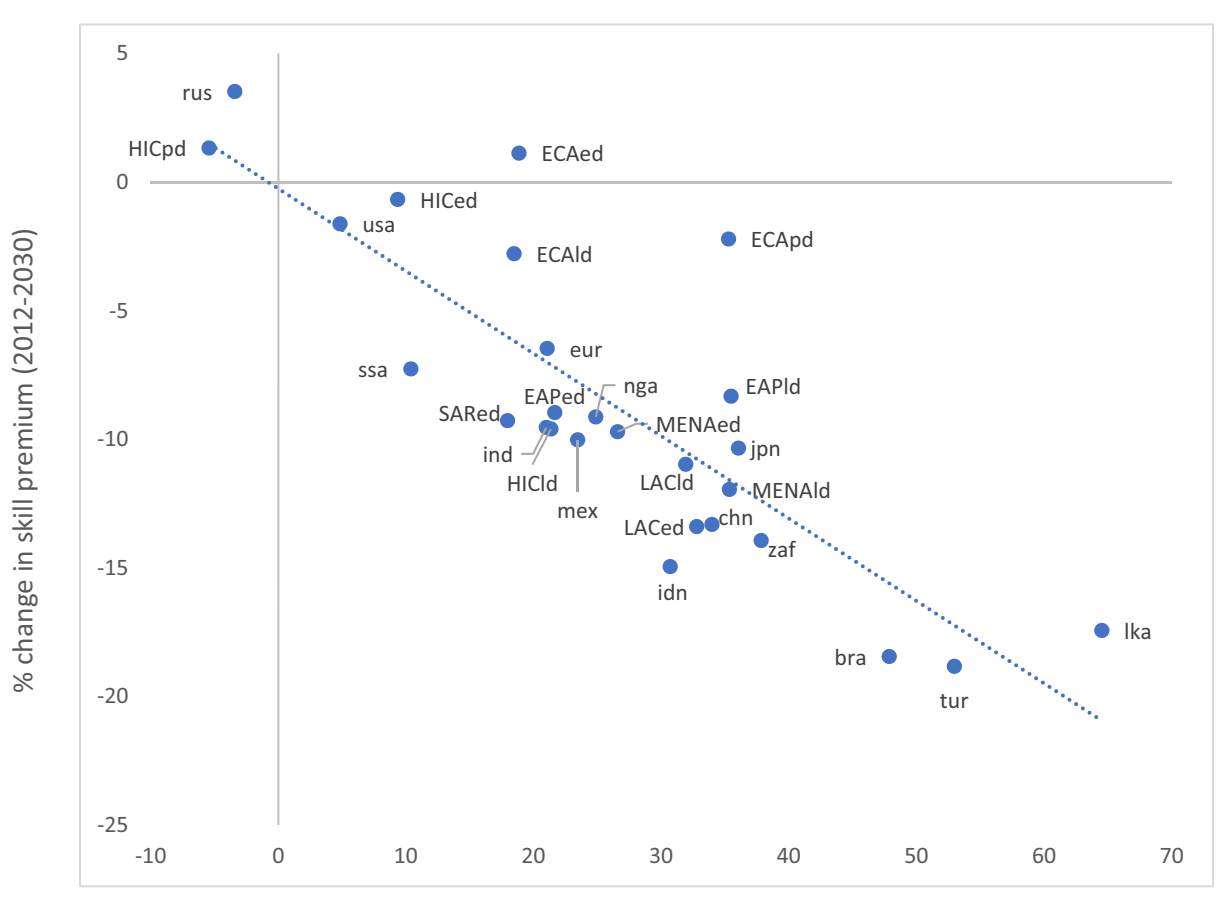

$\%$ change in relative skilled labor supply (2012-2030)

Fig. 6 The skill premium of wages versus the supply of skilled labor 2030 relative to 2012, in percent change, all sectors. Source: GIDD simulations. Note: Relative skill premium changes are calculated as: [(Wage_skill_2030/ Wage_unsk_2030) / (W_skill_2012/W_unsk_2012) - 1] × 100, and the same formula is used for relative labor supplies. Individual results are presented for selected countries: Brazil (BRA), China (CHN), India (IND), Indonesia (IDN), Japan (JPN), Mexico (MEX), Nigeria (NGA), Russia (RUS), South Africa (ZAF), Sri Lanka (LKA), and the United States (USA). Other countries are aggregated by regions, such as Sub-Saharan Africa (SSA) and European Union (EUR). For other regions, we follow the World Bank classification, including East Asia and Pacific (EAP), East Europe and Central Asia (ECA), Latin America and the Caribbean (LAC), Middle East and North of Africa (MENA), and South Asia (SAR), combined to the demographic typology described in Ahmed et al. (2016a, b, c), which divide countries according to their potential for demographic dividend by 2030, such as: early-dividend (ed), late dividend (lt), and post-dividend (pd); see Table A3 in Appendix 4 for more details

Compared to Lakner and Milanovic, our initial measure of Gini and Theil indices are smaller, which may be explained by differences in benchmark year, data sources, country coverage, and the slight improvement in equality when the education wave is measured by $2012 .^{32}$

What are the factors explaining the projected reduction in inequality? Using the Theil index, it is possible to decompose inequality between and within groups. The central panel of Table 4 shows the results of this decomposition when the groups are represented by either regions or countries. ${ }^{33}$ A clear answer emerges: global inequality decreases mainly because, on average,

\footnotetext{
$\overline{32}$ The latest year available in Lakner and Milanovic (2016) is 2008 for which the Gini is 70.5. Our initial year is 2012, for which our Gini index is 65.8. Thus, we focus the comparison on relative changes. Ferreira et al. (2015) describe the differences across several cross-national inequality databases.

${ }^{33}$ The regions are: Sub-Saharan Africa, Middle-East and North Africa, South Asia, East Asia and the Pacific, Europe and Central Asia, Latin America and the Caribbean, High Income countries. These regions correspond to the World Bank definitions.
} 


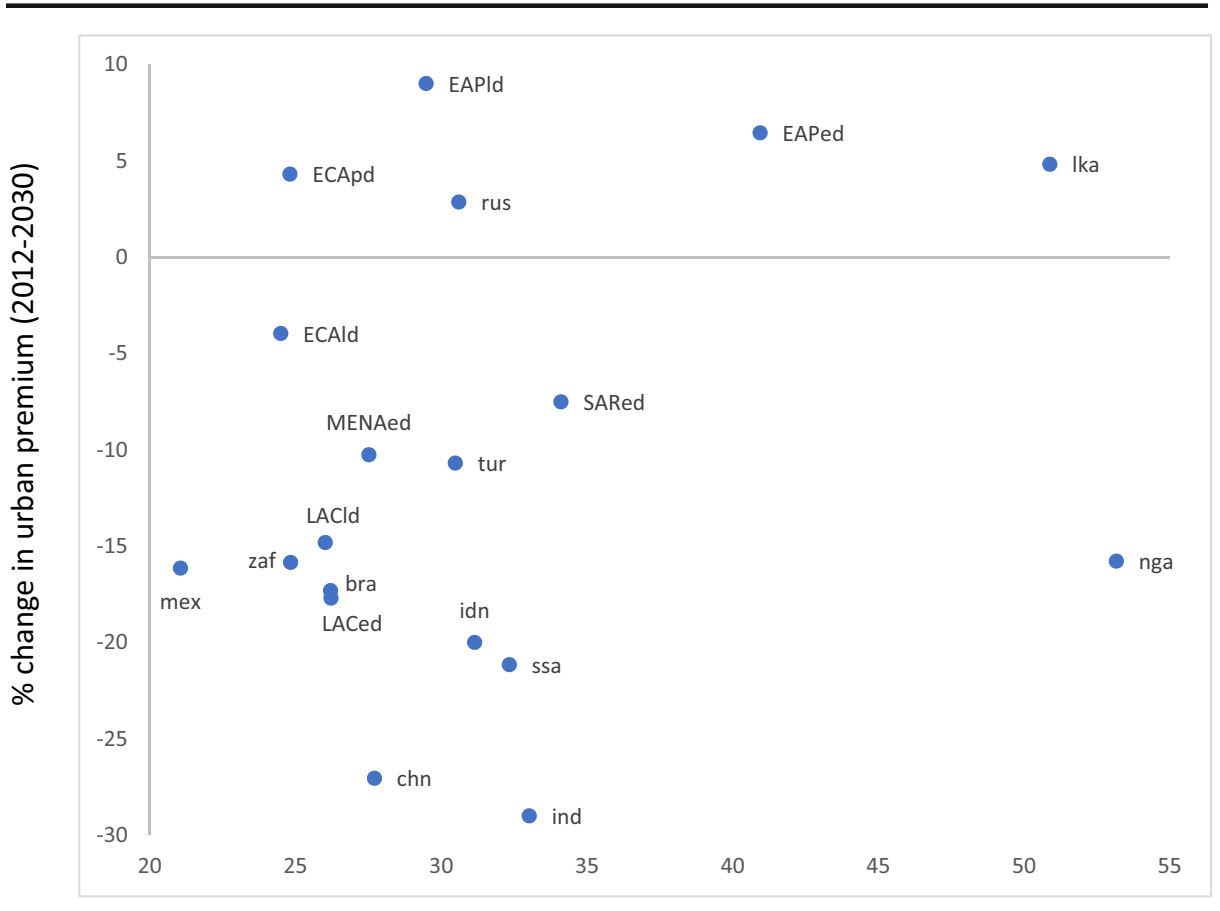

$\%$ change in relative urban employment (2012-2030)

Fig. 7 The urban premium of wages and the sector supply of labor for unskilled workers, 2030 relative to 2012, in percent change. Source: GIDD simulations. Note: Relative urban premium changes are calculated, just for the unskilled, as: [(Wage_non-agri_2030/Wage_agri_2030) / (Wage_no-agri_2012 / Wage_agri_2012) - 1] $\times 100$, and the same formula is used for relative employment. Individual results are presented for selected countries: Brazil (BRA), China (CHN), India (IND), Indonesia (IDN), Japan (JPN), Mexico (MEX), Nigeria (NGA), Russia (RUS), South Africa (ZAF), Sri Lanka (LKA), and the United States (USA). Other countries are aggregated by regions, such as Sub-Saharan Africa (SSA) and European Union (EUR). For other regions, we follow the World Bank classification, including East Asia and Pacific (EAP), East Europe and Central Asia (ECA), Latin America and the Caribbean (LAC), Middle East and North of Africa (MENA), and South Asia (SAR), combined to the demographic typology described in Ahmed et al. (2016a, b, c), which divide countries according to their potential for demographic dividend by 2030, such as early-dividend (ed), late dividend (lt), and post-dividend (pd); see Table A3 in Appendix 4 for more details

poorer countries are catching up. At the beginning of the period, the contribution of the 'betweengroups' component to total inequality is more than 50\% (52\% when using regions, $57 \%$ when using countries as groups). However, by the end of the period, the between-country component drops to less than $50 \%$ (due to income convergence) while the within-countries component shows a larger contribution to global inequality. This result does not imply that inequality within countries is increasing (more on this below), but that, at least, inequality between countries is decreasing at a faster pace. Poor and large countries, such as India and China, by growing fast are reshaping the global income distribution and contributing to the reduction of global inequality.

The importance of the education wave in the dynamics of inequality within countries can be seen by comparing the results of the education wave with those of the no-wave scenario in the last two columns of Table 4. The larger decreases of the skill premium in the education wave scenario pushes down inequality within countries, while this is not the case in the no-wave scenario. As a result, the within-group component in the no-wave scenario, as well as total inequality, are higher than those in the education wave. 
Table 4 Global inequality will go down in a more educated world

\begin{tabular}{lrrrr}
\hline Inequality measures & 2012 & \multicolumn{2}{l}{2030 - Education Wave } & \multirow{2}{*}{2030 - No Wave } \\
\cline { 3 - 4 } & & Demographic & Full simulation & \\
\hline Gini index & 65.8 & 65.5 & 62.6 & 63.2 \\
Theil & 90.7 & 91.0 & 76.6 & 78.6 \\
Theil Decompositions: & & & & 41.0 \\
Between regions (\%) & 51.7 & 48.0 & 41.4 & 59.0 \\
Within regions (\%) & 48.3 & 52.0 & 58.6 & 48.6 \\
Between countries (\%) & 57.2 & 53.6 & 49.1 & 51.4 \\
Within countries (\%) & 42.8 & 46.4 & 50.9 & 6.6 \\
Percentile 75 / Percentile 25 & 5.5 & 5.4 & 6.7 & 827.4 \\
Mean, \$(PPP) & 416.9 & 430.3 & 835.2 & 2.5 \\
Coeff. of variation & 3.1 & 3.3 & 2.4 & \\
\hline
\end{tabular}

Source: Authors' calculations based on GIDD projections

Comparing the global growth incidence curves (GICs) for the education wave and the nowave scenarios is another way of illustrating the change in the global distribution (Fig. 8). The shape of these GICs is similar to the elephant curve of Lakner and Milanovic (2016) but without the trunk part. The main reason for this difference is that Lakner and Milanovic use observed data, while the GICs in Fig. 8 are derived from a microsimulation model. In the period analyzed by Lakner and Milanovic, incomes of the richer people in richer countries grew at a fast pace generating the trunk in their GIC. ${ }^{34}$ However, the GIDD - using as inputs a growth rate of highincome countries lower than that of developing ones, and a reduction of the skill premia - does not generate high growth for the top percentiles, and thus does not generate a trunk.

These GICs highlight several interesting points. First, the education wave provides its highest benefits for the population with incomes between the bottom 20 and top 20; growth rates for the groups at the two extremes of the distribution are 1 to 2 percentage points lower than for the group in the middle. Second, the no-education wave rates of income expansion are below those of the education wave scenario for everyone with incomes up to about the 90th percentile. This is expected as the education wave is mainly a wave in the developing world. Third, the distance between the two lines appears small but, for the middle of the distribution and the bottom $5 \%$, the difference should not be underestimated. In fact, half a percentage point gap in growth rates accumulates to $10 \%$ larger incomes after 20 years, a non-trivial difference.

We also analyze the changes in the country composition of the bottom 20 - and the top-20\% of the global income distribution by 2030 (Table A2 of Appendix 2). In 2012, eight countries made up three-quarters of the population in the bottom 20 of the global distribution. And India and China alone accounted for almost $50 \%$ of it. Most of the other countries at the bottom were from Sub-Saharan Africa. For some of these countries, almost their entire national populations (or large shares of them) belonged to the global bottom 20 . While only $15 \%$ of Chinese nationals occupied the global bottom 20,97\% of the South African citizens resided in the bottom 20, $82 \%$ of those from Congo, and $60 \%$ of Nigerians. The composition changes significantly by 2030 . Notably, China disappears while India still contributes one-quarter to the total world population in the bottom 20. India's number corresponds to $23 \%$ of the total population of India, a lower share than the $30 \%$ of 2012. A similar evolution can be described for the top 20. With the arrival of China in

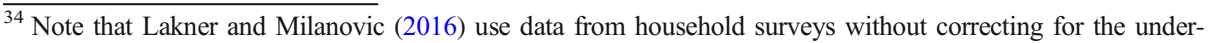
sampling of very wealthy individuals.
} 


\section{The education wave versus and the no-wave scenario}

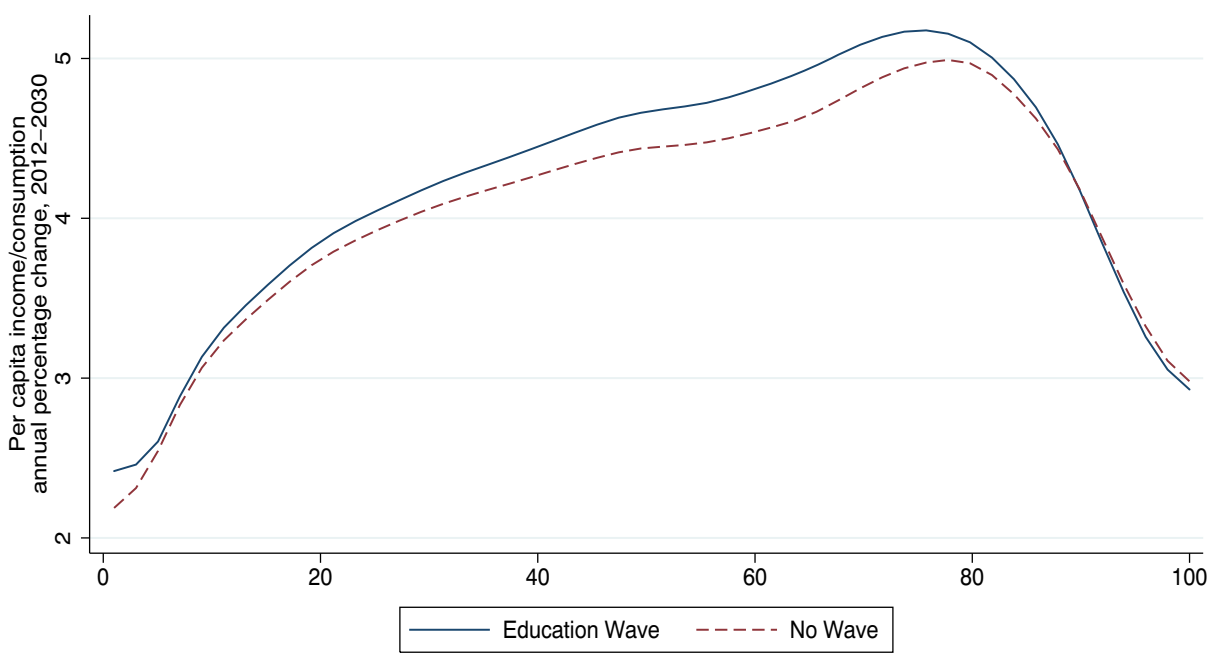

Fig. 8 Global Growth incidence curves The education wave versus and the no-wave scenario. Source: Authors' calculations based on GIDD projections

2030, a large percentage of citizens from the US and Western European countries will lose their top positions.

\subsubsection{Select countries}

The education wave has also strong influences on within-country distributions. In general, these national distributions tend to become more equal, but there is quite a bit of heterogeneity. The different dynamic changes depend on both quantity and price effects. Contrast, for example, the incidence curve for the education wave observed in Turkey versus that of Russia. The growth incidence curve for the full shock of the education wave, shown in panel a of Fig. 9, seems rather flat for Turkey and progressive (downward sloping) for Russia. This appears counterintuitive, given that Turkey is one of the countries where the skill premia are going down the most, while Russia is at the opposite end with a slight increase of the skill premia (see Fig. 6). However, the change in the skill premia is not the only channel through which distributions are shifting. Demographic change, including both aging and increased average years of schooling, contributes to the transformation of the distributions. In Turkey, the demographic shock is regressive. ${ }^{35}$ This demographic effect alone is depicted by the dotted regressive incidence curve (still shown in panel a). ${ }^{36}$ The fact that the demographic impact is regressive should not be too surprising. Deaton and Paxson (1998) show that there is a quite strong age effect on inequality, meaning that as cohorts age their inequality increases. Thus, rapidly aging societies, such as Turkey during the 2012-2030 period, are expected to be more

\footnotetext{
${ }^{35}$ We reweight the households so that the simulated population matches, in terms of its shares of age and education groups, the projected 2030 demographic structure is not distributional neutral. In fact, households with older and more educated members get reweighted more heavily than other households.

${ }^{36}$ Note that the dotted GIC is obtained using equation (4'), where the rewards are kept constant but the quantities of the assets or characteristics are changed.
} 
a: full effect
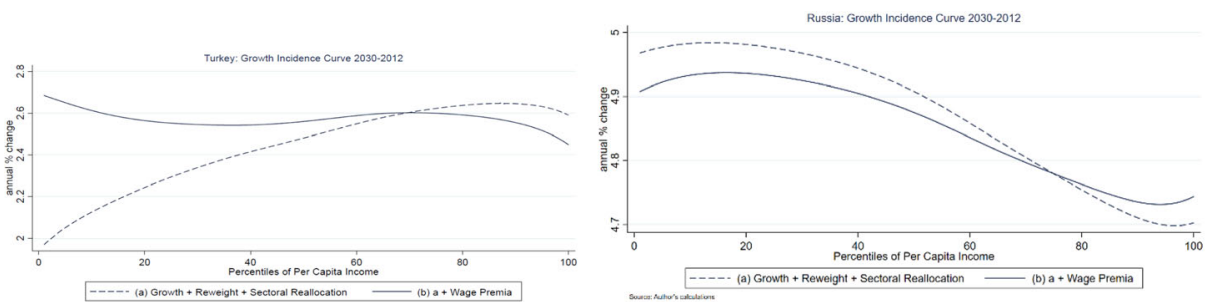

b: Net wage skill premia effect in the growth incidence curve
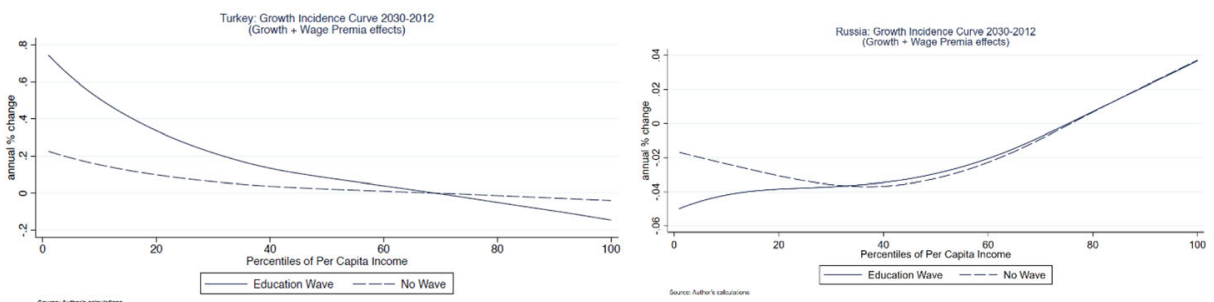

Fig. 9 Growth incidence curves for Turkey and Russia Panel a full effect. Panel b Net wage skill premia effect in the growth incidence curve

unequal. In the case of Russia, the demographic effect is also progressive. ${ }^{37}$ The isolated effect of the wage premia shows, as expected, a progressive GIC. This effect can be inferred by calculating the difference between the demographic and the full effect GICs. This net effect is shown in panel $b$, where it is progressive for Turkey and regressive for Russia. Also, unsurprisingly, the 'net' GICs for the no-wave scenario are flatter for both countries.

In the case of China, the growth incidence curve is shaped like an inverted $U$ due to the demographic effect, and the change in skill and urban premium are jointly and slightly regressive (Fig. 10a).

The expansion of the skilled workers in China will occur in the middle of the distribution. For each percentile of the population, we compare the share of workers that are skilled and unskilled both at the beginning of the period and at the end of the period during the education wave (Fig. 10b). This comparison tells us that most of the skilled are towards the top and most of the unskilled towards the bottom, but also that the shift caused by the education wave is concentrated in the middle of the income distribution. We also find that skilled workers expand in the middle and substitute for the contraction of the unskilled, also in the middle of the income distribution (Fig. 10c). In the case of China, the GIC is mainly shaped by changes in quantities rather than prices.

A final graph for the US (Fig. 11) illustrates what may happen to high income countries. The graph shows the density distribution for the US population by plotting the percentages of the US population that are found at different levels of income. In the graph, these levels of income are represented by the percentiles of the global income distribution. So clearly, most of

\footnotetext{
${ }^{37}$ In Russia this effect of demographic change on inequality, opposite to that in Turkey, is due to two reasons. Firstly, Russia is ageing during the simulation period, but less rapidly than Turkey. Secondly, the reweighting process increases the share of household groups (slightly older and less skilled) that tend to have lower withingroup inequality. As these groups become larger, they drag down overall inequality, which Figure 10 shows as a progressive growth incidence curve.
} 
a) Decomposition of the growth incidence curve

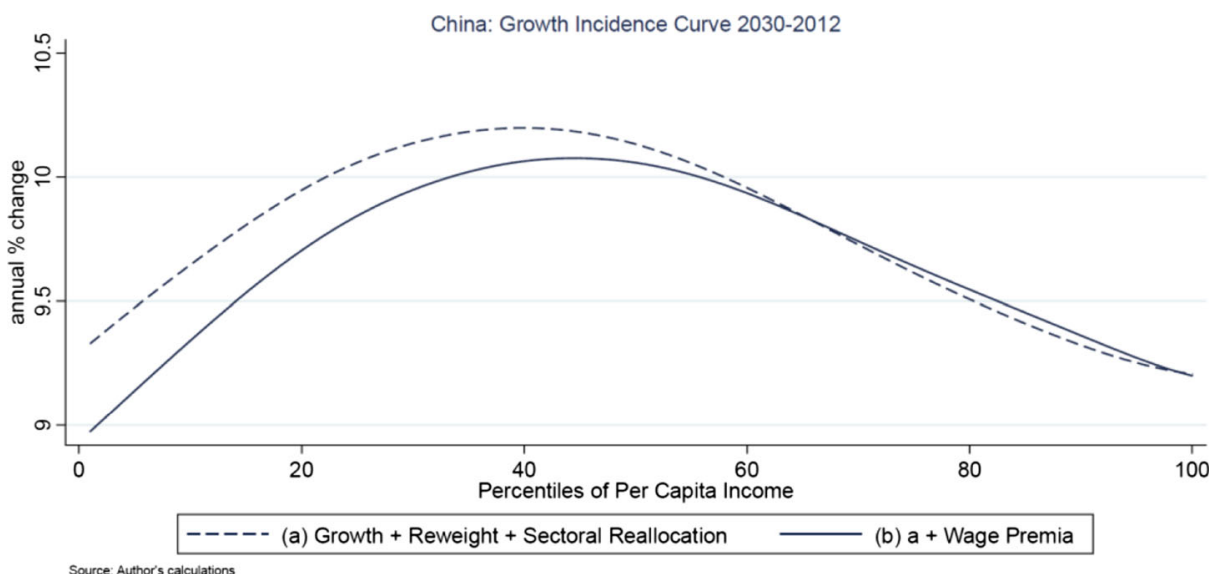

Source: Author's calculations

b) Skill level by income decile

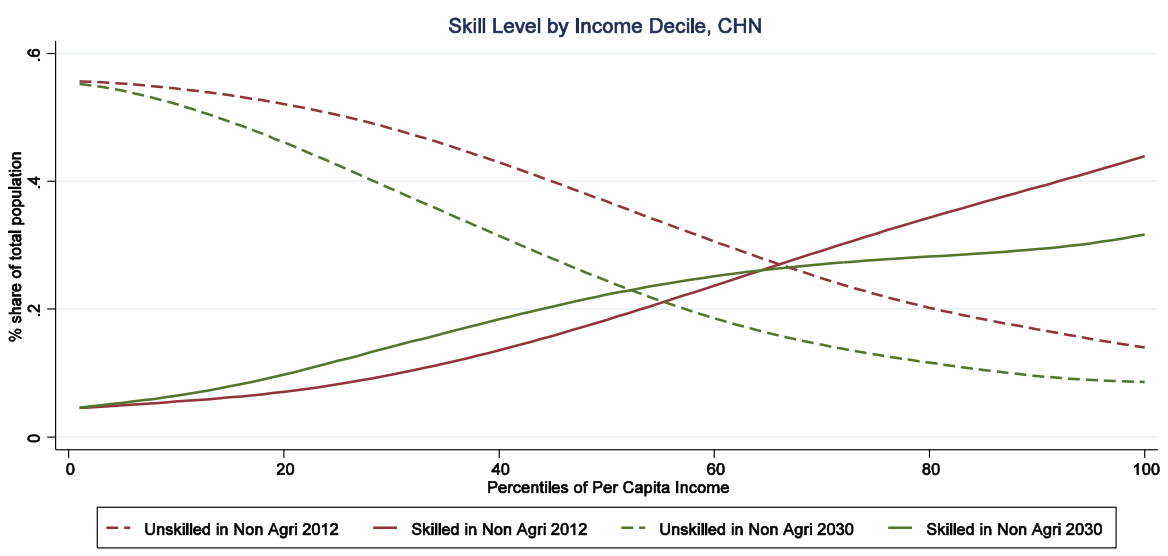

c) Difference in Skill level by income decile

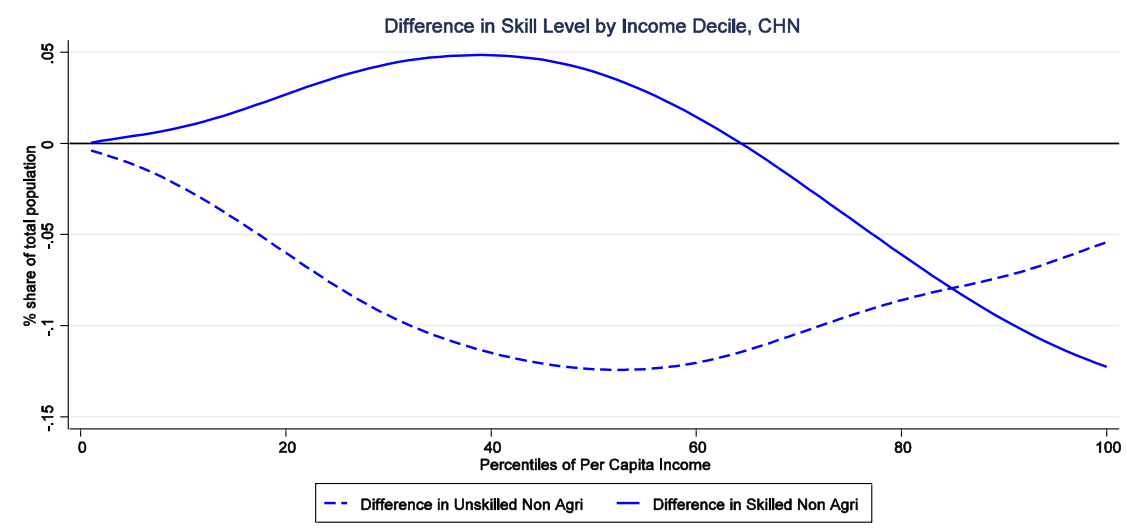

Fig. 10 Growth incidence curve for China 


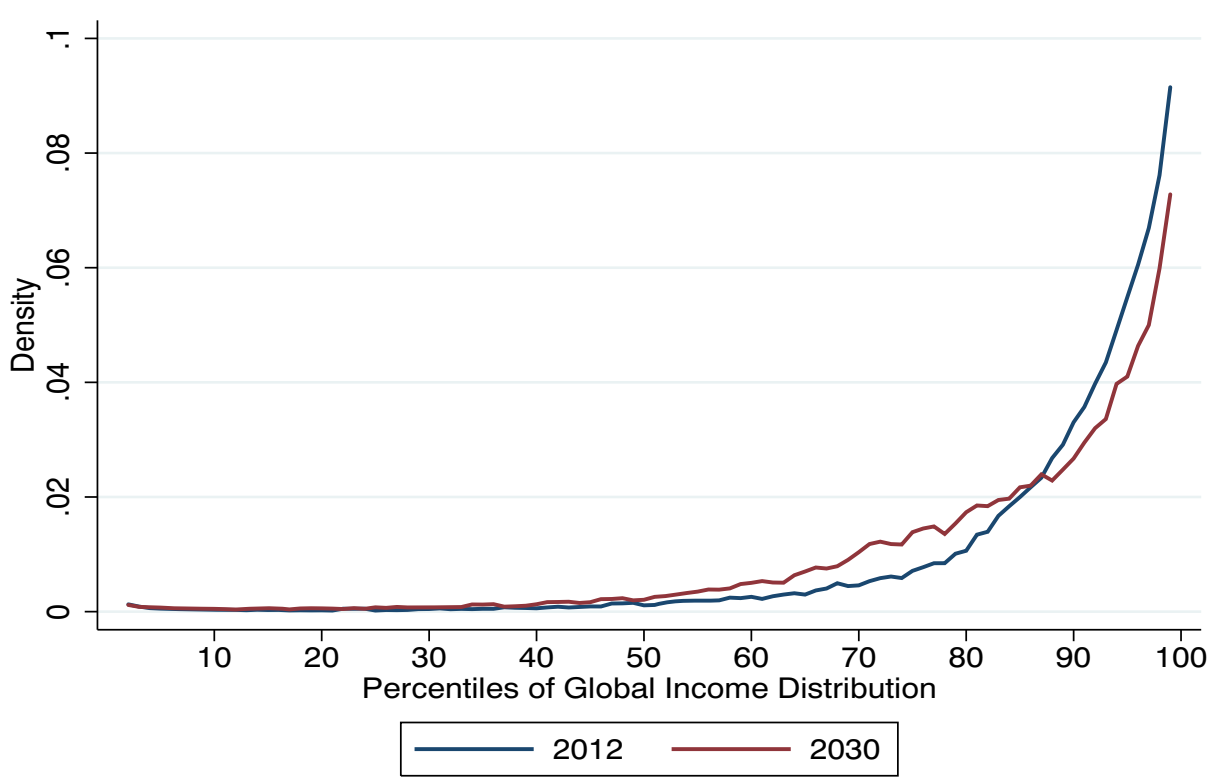

Fig. 11 Distribution of the US population across the world income distribution, in 2012 and 2030. Source: Authors' calculations

the US population is found at the top of the world distribution. However, it is interesting to note that the US will lose its dominance at the top, and by 2030, a larger share of US citizens will be in lower positions. This is a result of both income convergence across countries (citizens from other countries will start occupying the higher positions in the world distribution of income), but also of the pressure on the upper middle-income class in the US.

Notwithstanding the potential pressures on high income countries, overall the education wave will be pushing down inequality within countries. The Gini index is lower for almost all countries in the education wave when compared to the case of the no education wave.

Figure 12 plots the difference in the Gini index by 2030 between the education wave and no education-wave scenarios for each country. A negative number denotes less inequality (an improvement) brought about by the education wave. For most of the 117 countries covered, changes in the within-country inequality are more favorable with the education wave. Although this improvement does not completely reverse the increase in the contribution of within-country inequality to global inequality by 2030 (as shown in Table 4), it contains the increase.

\subsection{Sensitivity tests}

In addition to the convergence of mean incomes across countries, the reduction of global inequality examined up to this point is due to the reduction of the skill premium which in turn

Fig. 12 Difference in the Gini Index between Education and No Wave, by Country, 2030. Source: Authors' calculations. Note: Results based on microsimulation for individual countries. The re-weight procedure is based on the projected population in 2030, taking into account changes in the size and number of skilled workers by age cohort for each country between 2011 and 2030 


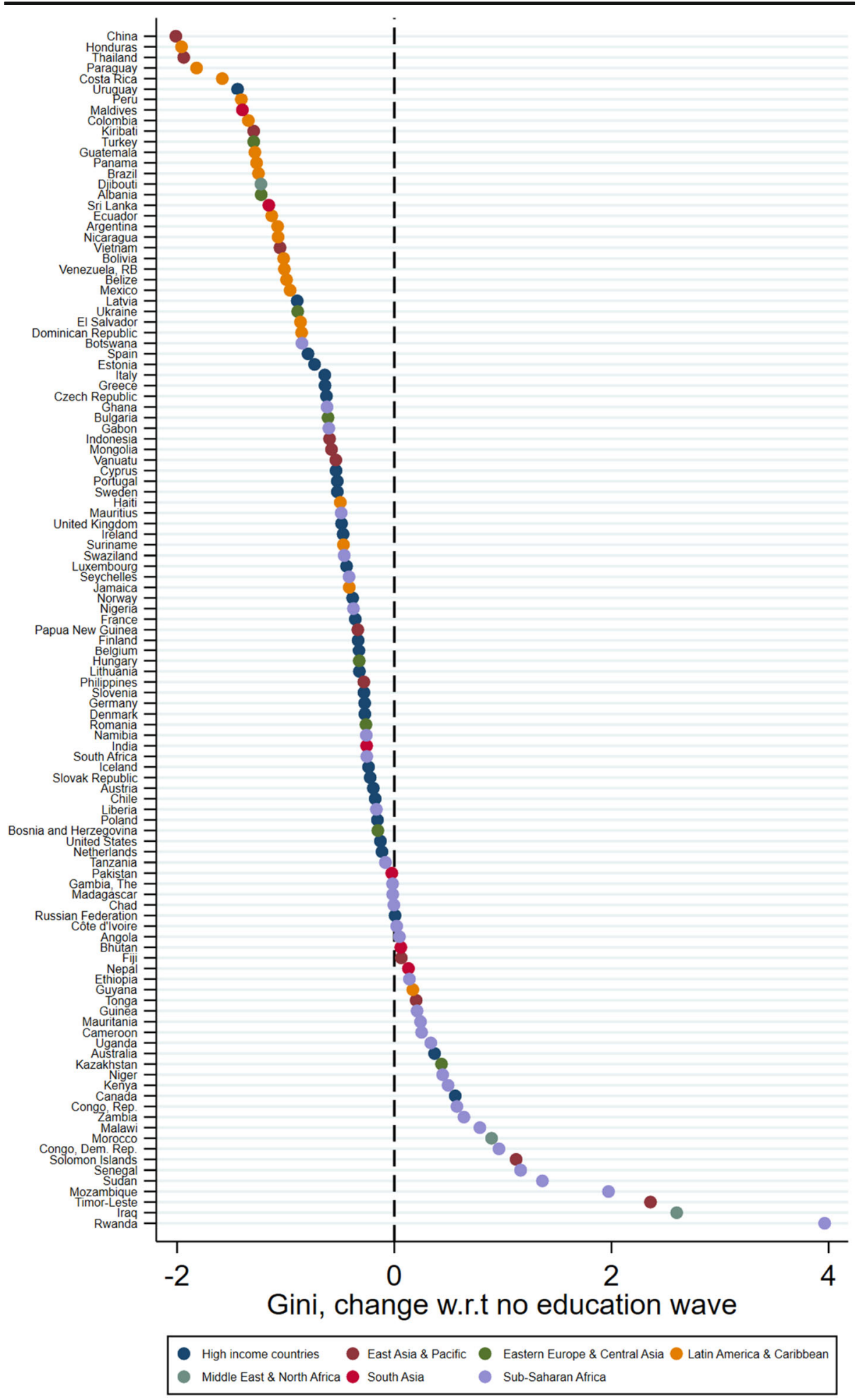


Table 5 Effect of education wave on global inequality for different scenarios

\begin{tabular}{lcccr}
\hline & $\begin{array}{l}\text { Education } \\
\text { wave }\end{array}$ & $\begin{array}{l}\text { No education } \\
\text { wave }\end{array}$ & $\begin{array}{l}\text { ST-1 } \\
\text { higher elasticity }\end{array}$ & $\begin{array}{l}\text { ST-2 } \\
\text { Alt. nesting }\end{array}$ \\
\hline Gini index & 62.6 & 63.2 & 62.6 & 63 \\
Theil & 76.6 & 78.6 & 76.5 & 77.8 \\
Theil Decompositions: & & & & 42.0 \\
Between regions (\%) & 41.4 & 41.0 & 51.4 & 58.0 \\
Within regions (\%) & 58.6 & 59.0 & 49.6 & 49.6 \\
Between countries (\%) & 49.1 & 48.6 & 50.8 & 50.4 \\
Within countries (\%) & 50.9 & 51.4 & 6.8 & 39.7 \\
Percentile 75 / Percentile 25 & 6.7 & 6.6 & 38.9 & 801.1 \\
Within-Theil by country & 39 & 40.4 & 841.7 & 2.3 \\
Mean, \$(PPP) & 835.2 & 827.4 & 2.4 & 2.4 \\
Coeff. of variation & 2.4 & 2.5 & & \\
\hline
\end{tabular}

Source: Authors' calculations. Notes: ST1: Higher elasticity. The baseline with a higher elasticity of substitution between skilled labor and capital of 3, instead of 2. Skilled labor and capital are bundled together in the same nest, and together substitutable to unskilled labor; ST2: Alternative nesting structure. The baseline with an alternative nesting structure of production inputs. Skilled and unskilled are directly substitutable with one another in the same nest, and together substitutable with capital

is related to the entry of skilled workers, a supply side phenomenon. However, as Tinbergen (1974) pointed out, technological progress that increases demand for skilled workers can offset the impact of the education wave. Acemoglu and Autor (2011), focusing on the US, describe how investments in human capital have played a major equalizing role but that, especially in the most recent three decades, skill-biased technological change has been a major force in pushing up the college premium and thus contributing to increasing inequality.

Given its important role in the past, it is useful to test how sensitive our global inequality results are to the demand side, or technological, change. Note that our exercise is not a forecasting exercise. Our aim is not to determine the most likely level of future inequality, but to conduct a what-if analysis to assess the relative magnitude of different factors in influencing the evolution of income distribution. The main insight from the sensitivity tests is that our results are robust or, in other words, that the contribution of the supply factor - of the education wave - remains relevant and is not easily counterbalanced by demand-side factors.

This main insight needs to be qualified. The sensitivity tests conducted here are not full simulations of alternative paths for technological progress, they are just close resemblances. It also remains possible that more intense technological transformations could overturn these results. The first sensitivity test (ST-1) raises the elasticity of substitution between skilled labor and capital to mimic the effects of biased technological change. This is suggested by the growth literature which focusses on the rental-wage ratios. This literature explains that the lack of effects of capital accumulation on the rental-wage ratios in advanced economies is due to labor-augmenting productivity (to offset having more capital goods available per worker). Yet, another way to account for the stability of rental-wage ratios comes from increases of the elasticity of substitution between the factors of production, as suggested by Houthakker (1955); Jones (2009); recently, de la Grandville and Solow (2017).

The increase of the elasticity of substitution in the production function - mimicking skilledbiased technological change - does not produce much effect for global inequality. The skill 
premia, as expected, go down less in this scenario then in the Education Wave scenario, and growth rates for quite a few developing countries increase slightly. Using these CGE model results with the microsimulations produces the outcomes shown in Table 5. Overall inequality does not change much vis-à-vis the standard Education Wave scenario and the slight reduction of overall inequality (76.5 vs 76.6 for the Theil) is coming from the within countries component (38.9 vs 39.0). ${ }^{38}$ Note that these are indeed small changes.

In the second sensitivity test (ST-2), an alternative nesting structure puts skilled and unskilled in one nest as imperfect substitutes, and their aggregate supply substitutes with capital in the next nest. In the standard production function, skilled labor and capital are nested together, reflecting a certain degree of complementarity among these two inputs which then, together as a bundle, substitute with unskilled labor. ${ }^{39}$ One could expect that the growth of skilled labor would dampen skill premia more given that the two labor types are directly substitutable in one nest. However, since the elasticities of substitution used in the standard and alternative set-ups are above 1, the different inputs are all imperfect substitutes of one another. Thus, the alternative nesting in the production function has a negligible impact on relative prices. In fact, in ST-2 the skill premia goes down almost as much as in the Education Wave scenario, while there is slightly less convergence of mean incomes across countries. These two CGE model results - skill premia and growth rates - are directly reflected in the movements of the inequality and its decomposition shown in Table 5. Overall inequality increases vis-à-vis the Education Wave scenario, and this increase of overall inequality (76.5 vs 76.6 for the Theil) is mainly coming from the between countries component (38.6 vs 37.6).

\section{Conclusion}

The sudden integration of China, India, and the former Soviet bloc of countries in the global economy has brought about the 'great doubling' (Freeman 2007) of the global labor markets and triggered significant changes in the global income distribution. This paper analyzes, in an ex-ante fashion, what is the impact of another 'great one-and-a-half times' shock to the global economy. Because their younger (and larger) populations and the still large positive gap in education of their young cohorts vis-à-vis their old ones, developing countries will soon be the sole contributors to the expansion of the global pool of skilled workers. Even without any improvement in education effort by 2030 , the ratio of skilled workers from developing countries to skilled workers from high income (OECD) countries will be 3 to 1, up from 2 to 1 in 2012; a 'one-and-a-half times' increase that this paper labels the education wave.

The main result of the analysis of the impact of this education wave is that global inequality will likely decrease. This is driven by a reduction of inequality between and within countries. Convergence of incomes per capita between countries, mainly depending on closing up of productivity gaps between high income and developing countries, is further boosted by the education wave. In addition, despite its increasingly larger weight in determining global inequality, within-country inequality would decrease in most countries. Education, especially

\footnotetext{
$\overline{38}$ This may appear counterintuitive given that the skill premia are going down less in this sensitivity test than in the education wave scenario. However, in the sensitivity test some countries with low within-country inequality slightly increase their weights (not shown in Table 5) in the decomposition, and that explains the aggregate results of the table.

${ }^{39}$ See footnote 22 for more details.
} 
for the developing world, can still play the role of the great equalizer. The results also show that the pressure on high income countries may still be on in the future.

We suggest a few areas for further research. To isolate the effects of labor supply and education on wages, particularly skill premia, the projections of labor supply and education are exogenous in the analysis. Although those trends are based on the stable pipeline effect, they may represent a lower bound. In fact, the supply of education may be influenced by changes in the returns to education or, as hypothesized by Acemoglu (1998), the supply may influence technological change and push up future demand for skilled work. Hence, interactions of demand and supply of education and their impact on inequality will require more sophisticated modeling in the future. Also, missing information about income from capital and its ownership distribution in household surveys will require triangulation with administrative and tax data to improve the analysis about how changes in capital income affect income distribution.

Acknowledgements We thank Christina Calvo, Francisco Ferreira, Ayhan Kose, Christoph Lakner, Maryla Maliszewska, Hans Timmer, Philip Schellekens, Jos Verbeek, and participants of seminars organized by the World Bank's Equity and Public Policy Practice Group, Development Prospects Group, Graduate Program in Economics at the Federal University of Parana, Brazil, and the 17th Annual Conference on Global Economic Analysis in Dakar, Senegal, for their useful comments. Kyun Chang, Nathaniel Russel, and Ivan Torre provided valuable research assistance. We also thank the support from the Knowledge for Change Partnership multi-donor trust fund. The views expressed in this paper are the authors' only.

Open Access This book is licensed under the terms of the Creative Commons Attribution 3.0 IGO License (https://creativecommons.org/licenses/by/3.0/igo/), which permits use, sharing, adaptation, distribution and reproduction in any medium or format, as long as you give appropriate credit to the World Bank, provide a link to the Creative Commons licence and indicate if changes were made.

The use of the World Bank's name, and the use of the World Bank's logo, shall be subject to a separate written licence agreement between the World Bank and the user and is not authorized as part of this CC-IGO licence. Note that the link provided above includes additional terms and conditions of the licence

The images or other third party material in this book are included in the book's Creative Commons licence, unless indicated otherwise in a credit line to the material. If material is not included in the book's Creative Commons licence and your intended use is not permitted by statutory regulation or exceeds the permitted use, you will need to obtain permission directly from the copyright holder.

\section{References}

Acemoglu, D.: Why do new technologies complement skills? Directed technical change and wage inequality. Q. J. Econ. 113(4), 1055-1089 (1998)

Acemoglu, D.: Technical change, inequality, and the labor market. J. Econ. Lit. 40(1), 7-72 (2002)

Acemoglu, D., D. Autor (2011) Skills, Tasks, and Technologies: Implications for Employment and Earnings. Handbook of Labor Economics. Vol 4B Elsevier

Ahmed, S. Amer, Cruz, Marcio, Quillin, Bryce, and Schellekens, Philip (2016b). "Demographic Change and Development: a Global Typology," Policy Research Working Paper Series 7893, The World Bank

Ahmed, S.A., Cruz, M., Go, D.S., Maliszewska, M., Osorio-Rodarte, I.: How significant is sub-Saharan Africa's demographic dividend for its future growth and poverty reduction? Rev. Dev. Econ. 20, 762-793 (2016a). https://doi.org/10.1111/rode.12227

Ahmed, S.A., D.S. Go, and D. Willenbockel (2016c). "Global Migration Revisited - Short-Term Pains, LongTerm Gains, and the Potential of South-South Migration." World Bank Policy Research Working Paper 7628

Almeida dos Reis, J.G., de Barros, R.P.: Wage inequality and the distribution of education: a study of the evolution of regional differences in inequality in metropolitan Brazil. J. Dev. Econ. 36(1), 117-143 (1991)

Anand, S., Segal, A.: What do we know about global income inequality? J. Econ. Lit. 46(1), 57-94 (2008)

Atkinson, A., Brandolini, A.: On analyzing the world distribution of income. World Bank Econ. Rev. 24(1), 1$37(2010)$

Atkinson, A.: Inequality - What Can Be Done? Harvard University Press, Cambrige (2015) 
Autor, D., Dorn, D., Hanson, G, and Majlesi, K. (2016). "Importing political polarization? The electoral consequences of rising trade exposure." NBER working paper 22637

Aziz, O.A., Ball, C., Creedy, J., Eedrah, J.: The distributional impact of population ageing. In: Treasury Working Paper Series 13/13. Treasury, New Zealand (2013)

Barro, R. J. and Lee, J. W. (2013) A new data set of educational attainment in the world, 1950-2010. Journal of development economics, n. 104 (2013)

Bosworth, B., Collins, S.M.: The empirics of growth: an update. Brook. Pap. Econ. Act. 2003(2), 113-206 (2003)

Bourguignon, B., Morrisson, C.: Inequality among world citizens: 1820-1992. Am. Econ. Rev. 92(4), 727-744 (2002)

Bourguignon, F.: The Globalization of Inequality. Princeton University Press, Princeton (2015)

Bourguignon, F., and Bussolo, M. 2013. "Income Distribution in Computable General Equilibrium Modeling." In Dixon, P.B., and D.W. Jorgenson (eds.), Handbook of Computable General Equilibrium Modeling Vol.1A. Amsterdam: North-Holland

Bourguignon, F., Ferreira, F.H., and Lustig, N. (2005). The Microeconomics of Income Distribution Dynamics in East Asia and Latin America. The World Bank

Bourguignon, F., Bussolo, M. and Da Silva, L.P. (2008) The Impact of Macroeconomic Policies on Poverty and Income Distribution: Macro-Micro Evaluation Techniques and Tools. World Bank

Bussolo, M., de Hoyos, R.E., and Medvedev D. (2010) Economic growth and income distribution: linking macroeconomic models with household survey data at the global level. Int. J. Microsimul. 92-103

Bussolo M., de Hoyos, R. E., Medvedev, D., Van der Mensbrugghe D., (2012). "Global Growth and Distribution: China, India, and the Emergence of a Global Middle Class," Journal of Globalization and Development, De Gruyter, vol. 2(2), pages 1-29, January

Cruz M., Go, D.S., Osório-Rodarte, I. (2017) Modeling the Poverty and Distribution Effects of Human Capital Formation across Countries: Using a New Database on Labor Skills and Wages. World Bank, Manuscript

Cruz, M. and Milet, E. (2017) Skill Premia in Developing Countries. World Bank, Manuscript

de la Granville, O.: Economic Growth - a Unified Approach, 2nd edn. Cambridge University Press, Cambridge (2017)

Deaton, A., Paxson, C.: Economies of scale, household size, and the demand for food. J. Polit. Econ. 106(5), 897-930 (1998)

Dellink, R., Chateau, J., Lanzi, E., Magné, B.: Long-term economic growth projections in the shared socioeconomic pathways. Glob. Environ. Chang. 42(January), 200-214 (2017)

Devarajan, S., Go, D.S., and Li, H. (1999). "Quantifying the fiscal effects of trade reform." Policy Research Working Paper Series 2162, The World Bank

Devarajan, S., Go, D.S., Maliszewska, M., Osorio-Rodarte, I., Timmer, H.: Stress-testing Africa's growth and poverty performance. J. Policy Model. 37(4), 521-547 (2015)

Dolls, M., Doorley, K., Paulus, A., Schneider, H., Sommer, E.: Demographic change and the European income distribution. J. Econ. Inequal. 17(3), 337-357 (2019)

Edwards, R., and Lange, F. (2013). The US Labor Market in 2030: A Scenario Based on Current Trends in Supply and Demand. IZA Discussion Paper No. 7825

Ferreira, F.H., Lustig, N. \& Teles, D. J. Econ. Inequal. (2015) 13: 497, Appraising cross-national income inequality databases: An introduction, 526

Freeman, R.B.: Are Your Wages Set in Beijing? Journal of Economic Perspectives. 9(3), 15-32 (1995)

Freeman, R.B.: The great doubling: the challenge of the new global labor market. In: Edwards, J., Crain, M., Lalleberg, A.L. (eds.) Ending Poverty in America: how to Restore the American Dream. The New Press, New York (2007)

Freeman, R. B. (2008). "The new global labor market." Focus 26(1) summer-fall 2008, pp. 1-6

Galbraigth, J.K.: Inequality and Instability. Oxford University Press, Oxford (2012)

GTAP (Global Trade Analysis Project): GTAP data base version 9. Purdue University (2015) https://www.gtap. agecon.purdue.edu/default.asp

Hillberry, R., Hummels, D.: Trade Elasticity Parameters for a Computable General Equilibrium Model. In: Dixon, P.B., Jorgenson, D.W. (eds.) Handbook of Computable General Equilibrium Modeling, Vol 1B. North-Holland, Amsterdam (2013)

Hillebrand, E.: The global distribution of income in 2050. World Dev. 36(5), 727-740 (2008)

Houthakker, H.S.: The Pareto Distribtuion and the cobb-Douglas production function in activity analysis. Rev. Econ. Stud. 23, 27-31 (1955)

Jones, C.I.: The shape of production functions and the direction of technical change. Q. J. Econ. 2, 517-549 (2009)

Lakner, C., Milanovic, B.: Global income distribution: from the fall of the berlin wall to the great recession. World Bank Econ. Rev. 30(2), 203-232 (2016)

León-Ledesma, M., McAdam, P., Willman, A.: Identifying the elasticity of substitution with biased technical change. Am. Econ. Rev. 100(4), 1330-1357 (2010) 
Loichinger, E.: Labor force projections up to 2053 for 26 EU countries, by age, sex, and highest level of educational attainment. Demogr. Res. 32(15), 443-486 (2015)

López-Calva, L.F., and Lustig, N. eds (2010) Declining inequality in Latin America: A decade of progress? Brookings Institution Press

Martin, W., Mitra, D.: Productivity Growth and Convergence in Agriculture and Manufacturing. In: Policy Research Working Paper Series 2171. Bank, The World (1999)

Milanovic, B.: Global income inequality in numbers: in history and now. Glob. Policy. 4(2), 198-208 (2013)

Milanovic, B.: True world income distribution, 1988 and 1993:First calculations based on household surveys alone. Econ J. 112(476), 51-92 (2002)

Milanovic, B.: Worlds Apart: Global and International Inequality, 1950-2000. Princeton University Press, Princeton, NJ (2005)

Montenegro, C.E., Hirn, M.L.: A new disaggregated set of labor market indicators using standardized household surveys from around the world. In: Background Paper for the World Development Report 2009, Reshaping Economic Geography. World Bank, Washington, DC (2009)

OECD (Organization for Economic Co-operation and Development): PISA 2015 Results: Excellence and Equity in Education. Vol. 1. OECD, Paris (2016)

Orcutt, G.H.: A new type of socio-economic system. Rev. Econ. Stat. 39(2), 116-123 (1957)

Piketty, T.: Capital in the Twenty-First Century. The Belknap Press of Harvard University Press, Cambridge (2014)

Ravallion, M.: How Long Will it Take to Lift One Billion People out of Poverty? World Bank Research Observer, World Bank Group, vol. 28(2), pp. 139-158 (2013)

Ravallion, M.: The developing world's bulging (but vulnerable) middle class. World Dev. 38(4), 445-454 (2010)

Reardon, T., Stamoulis, K., Pingali, P.: Rural nonfarm employment in developing countries in an era of globalization. Agric. Econ. 37(s1), 173-183 (2007)

Samir, KC., Barakat, B., Goujon, A., Skirbekk, V., Sanderson, W., Lutz, W.: Projection of populations by level of educational attainment, age, and sex for 120 countries for 2005-2050. Demogr. Res. 22(15), 383-472 (2010)

Solow, R.M.: A contribution to the theory of economic growth. Q. J. Econ. 70(1), 65-94 (1956)

Stiglitz, J.: The Price of Inequality -how Today's Divided Society Endangers our Future. W.W. Norton \& Company, New York (2012)

Tinbergen: Substitution of graduate by other labour. Kyklos. 27, 217-226 (1974)

UN (United Nations): The World Population Prospects - the 2015 Revision. United Nations, New York (2015)

Van Der Mensbrugghe, D. (2011). Linkage technical reference document, version 7.1. Development prospects group, the World Bank, Washington DC

World Bank: Global Economic Prospects 2007 - Managing the Next Wave of Globalization. The World Bank, Washington DC (2007)

World Bank: Global Development Horizons 2011 - Multipolarity: the New Global Economy. The World Bank, Washington DC (2011)

World Bank: Global Monitoring Report 2015/16: Development Goals in an Era of Demographic Change. World Bank, Washington DC (2015)

World Bank: Poverty and Shared Prosperity 2016: Taking on Inequality. World Bank, Washington DC (2016)

Publisher's Note Springer Nature remains neutral with regard to jurisdictional claims in published maps and institutional affiliations. 